Supporting information for

\title{
In Situ Visualization of Atmosphere-dependent Relaxation and Failure in Energy Storage Electrodes
}

\author{
Chao Wang, ${ }^{\mathrm{a}, \mathrm{b}}$ Caixia Meng, ${ }^{\mathrm{a}}$ Shiwen Li,,${ }^{\mathrm{a}, \mathrm{b}}$ Guohui Zhang, ${ }^{\mathrm{a}}$ Yanxiao Ning ${ }^{\mathrm{a}}$ and Qiang Fu $\mathrm{Fu}^{\mathrm{a}, \mathrm{c}^{*}}$ \\ [a] State Key Laboratory of Catalysis, iChEM, Dalian Institute of Chemical Physics, Chinese Academy of Sciences, Dalian 116023, \\ China. \\ [b] University of Chinese Academy of Sciences, Beijing 100049, China. \\ [c] Dalian National Laboratory for Clean Energy, Dalian Institute of Chemical Physics, Chinese Academy of Sciences, Dalian \\ 116023, China. \\ *Email: qfu@dicp.ac.cn
}




\section{Table of Contents}

Experimental Procedures ..................... 33

Results and discussion $\ldots \ldots \ldots \ldots \ldots \ldots \ldots \ldots$ S6

Supplementary Raman and XRD results. . . . . . . . . . . . S6

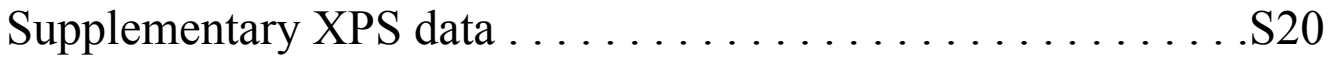

Supplementary electrochemical measurements results . . . . . . S35

In situ visualization of the failure behavior in LIB ..............S37

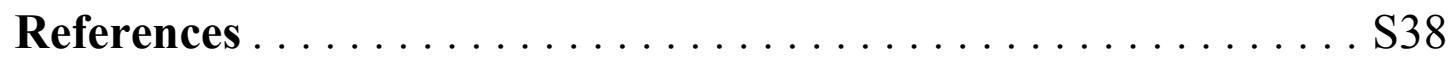




\section{Experimental procedures}

Materials. The ionic liquid (IL) electrolyte was prepared by mixing the vacuum-dried $\left(120{ }^{\circ} \mathrm{C}\right.$ for $20 \mathrm{~h}$ under $5 \times 10^{-6}$ mbar) 1-ethyl-3-methylimidazolium chloride (EMICl, 99\%, Lanzhou Institute of Chemical Physics, Chinese Academy of Sciences) with anhydrous aluminum chloride $\left(\mathrm{AlCl}_{3}\right.$, Alfa Aesar, 99.999\%) in an Ar-filled glove box (MBRAUN, $\mathrm{H}_{2} \mathrm{O} \& \mathrm{O}_{2}<0.5 \mathrm{ppm}$ ). The molar ratio of $\mathrm{EMICl}$ to $\mathrm{AlCl}_{3}$ is $1: 1.3$, which is regarded to be optimal for the battery performance. ${ }^{1}$ All the solids were dissolved under continual magnetic stirring condition and finally formed a transparent lightyellow liquid. The electrode materials: HOPG (Bruker, Grade-ZYB, $12 \times 12 \mathrm{~mm}^{2}$ ) and high purity Al foil (Alfa Asesar, 99.45\%, thickness of $0.025 \mathrm{~mm}$ ) were both commercially purchased.

Operando/in situ characterization methods. Operando/in situ Raman and XPS measurements of both intercalation and failure processes were based on a planar Al/HOPG model battery as described in our previous work. ${ }^{2}$ An HOPG flake (cleaved from a HOPG crystal using the Scotch tape method) and an Al foil were parallelly placed on an insulating surface (e.g. glass) with a $\sim 1 \mathrm{~mm}$ gap in between. An ILimpregnated glass fiber separator (Whatman GF/D, $5 \mathrm{~mm} \times 5 \mathrm{~mm}$ ) was placed in between. For operando/in situ XPS measurements, the Al/HOPG model battery was assembled onto an Omicron-type direct-current heating sample holder. The HOPG flake $\left(5 \times 12 \mathrm{~mm}^{2}\right)$ was connected with the sample holder and thus grounded. A small piece of glass fiber separator layer soaked in IL was placed on one end of the HOPG flake.

Raman measurements were carried out in an in situ Raman cell which could control the atmosphere (ambient pressure) and electrode potential. All the batteries and cell assembling were operated in an Ar-filled glove box $\left(\mathrm{H}_{2} \mathrm{O}, \mathrm{O}_{2}<0.5 \mathrm{ppm}\right)$. Raman spectra were recorded with a LabRAM HR 800 Raman spectrometer using a $532 \mathrm{~nm}$ laser. The Raman laser beams were always focused on the open region of the HOPG electrode in the planar model battery.

XPS measurements were carried out using a SPECS XPS spectrometer equipped with a $\mathrm{Mg} \mathrm{K} \alpha \mathrm{X}$-ray source (1253.6 eV at $200 \mathrm{~W}$ ) and a PHOIBOS 100 hemispherical energy analyzer. Survey spectra and core level spectra were recorded under ultrahigh vacuum 
(UHV) conditions ( $\mathrm{p}<5 \times 10^{-9} \mathrm{mbar}$ ) using a pass energy of $20 \mathrm{eV}$. Data analysis was done by the Casa-XPS software with a Shirley background and 70/30 GaussianLorentzian fits. The assembled model batteries were transferred to the XPS analysis system by a mobile UHV transfer chamber. The depth-dependent chemical information in near surface region was collected with angle-resolved XPS (ARXPS) by analyzing the grazing emission electron in different angles. During ARXPS measurements, the sample was rotated to the selected angle while the angle between X-ray and analyzer was consistent.

XRD measurements were carried out in an operando XRD cell with Kapton film window (Beijing Scistar Technology Co. Ltd). The XRD patterns were recorded by SmartLab XRD (Rigaku, Japan). The data scale is $20-30^{\circ}$ with $5^{\circ} / \mathrm{min}$.

All the electrochemical measurements were performed on a $\mathrm{CHI} 660 \mathrm{E}$ electrochemical work station (Chen Hua company, Shanghai, China).

Gas treatment methods. For the in situ measurements in anhydrous $\mathrm{Ar}\left(\mathrm{H}_{2} \mathrm{O}\right.$ and $\mathrm{O}_{2}$ $<0.5 \mathrm{ppm}) / \mathrm{UHV}$, the samples were sealed in a custom-built Raman/XRD cell or in XPS UHV chamber under OC condition. The Raman spectra and XRD pattern of the sample after being exposed to air were acquired by directly disassembling the Raman/XRD cell. The dynamic analysis of atmosphere-dependent stage-degradation by in situ Raman was carried out in the Raman cell equipped with a gas circulation system (Figure $\mathrm{S} 1)$. The flow rate of the $\mathrm{N}_{2}$ and $\mathrm{O}_{2}(99.999 \%$, without further purified) was $100 \mathrm{sccm}(\mathrm{mL} / \mathrm{min})$. The hydrous atmosphere was obtained by bubbling DI water with the selected gas using the same flow rate. For the in situ XPS measurements, the low pressure $\mathrm{O}_{2}$ treatment was carried out via exposure to $1 \times 10^{-6} \mathrm{mbar}_{2}$ in XPS UHV chamber equipped with a $\mathrm{O}_{2}$ leak valve. The XPS core-level signals were collected after gas treatment when the pressure was lower than $5 \times 10^{-9}$ mbar. The $\mathrm{H}_{2} \mathrm{O}$ treatment was performed by exposure to hydrous $\operatorname{Ar}(100 \mathrm{sccm}$, bubbling DI water) in the UHV transfer chamber (background vacuum $\sim 10^{-7} \mathrm{mbar}$ ) as shown in Figure S26. The in situ XPS measurements after exposure can be described as: charging under UHV (measured by operando XPS) - OC - exposure to $1 \times 10^{-6} \mathrm{mbar}_{2} / 1$ atm hydrous $\mathrm{Ar}$ evacuation to UHV - XPS data acquisition. 
Electrochemical measurements of the coin type Al/graphite battery. The graphite electrode was prepared by mixing the nano graphite powder (from XF Nano, China) and binder (Polyvinylidene Fluoride, PVDF) in N-methyl-2-pyrrolidone (NMP) and then pasted onto the surface of a Ta foil current collector. The mass ratio of the active graphite material and binder was 9:1. An Al foil (thickness of $0.1 \mathrm{~mm}$, Alfa Asesar, 99.99\%) was used as the anode and a glass fiber paper (Whatman GF/D) as the separator. The graphite cathode, the separator and the $\mathrm{Al}$ anode were stacked together to form a sandwich coin-type battery and sealed in the in situ Raman cell (Figure S1) in which the atmosphere and current/potential can be controlled. The OCV decay and CV curves were recorded by the $\mathrm{CHI} 660 \mathrm{E}$ electrochemical work station (Chen Hua company, Shanghai, China). The GCD profiles and cycling performance were measured by a LAND CT2001A battery tester (LANBTS, Wuhan, China). 


\section{Results and discussion}

\section{Supplementary Raman and XRD results}

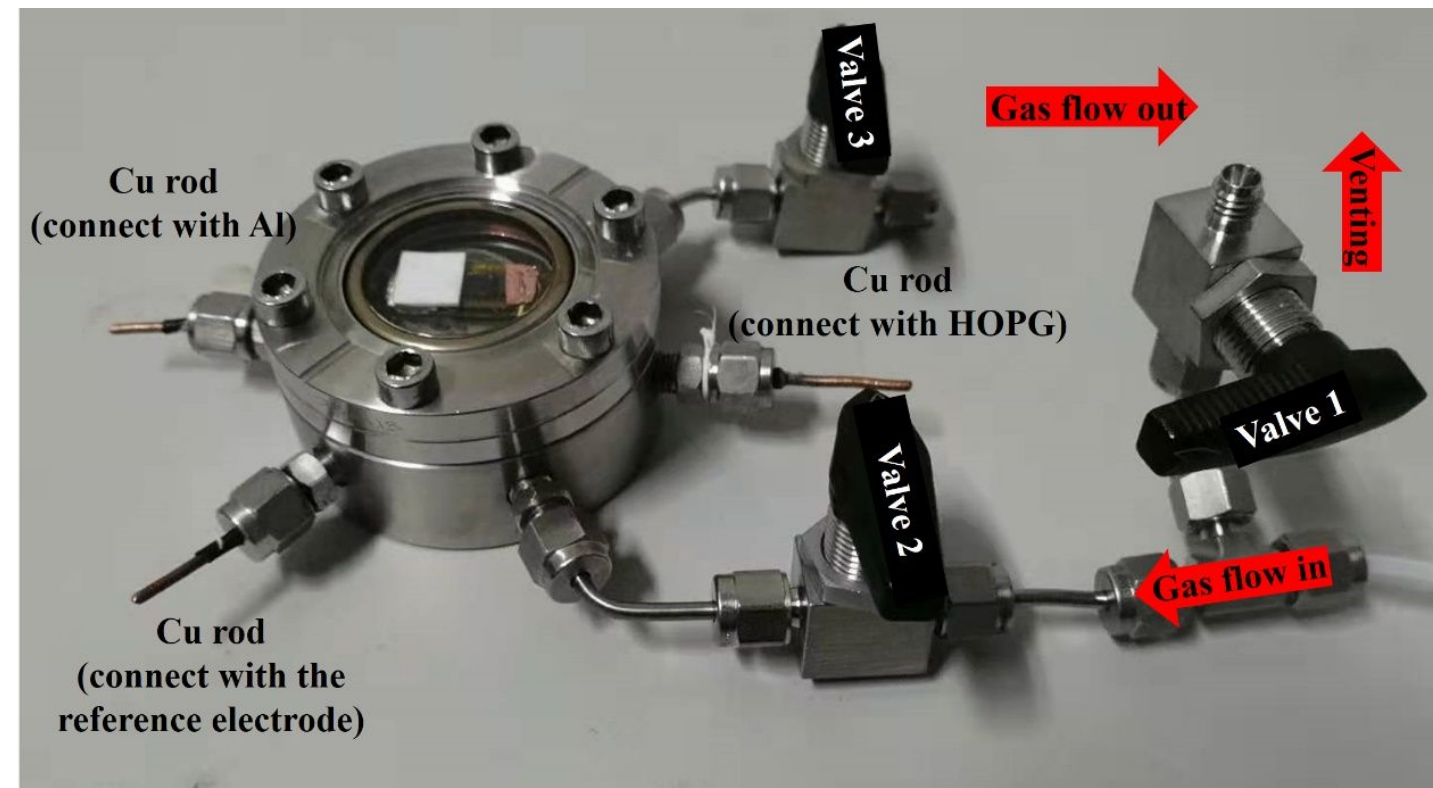

Figure S1. Photo of the in situ Raman cell which can control the atmosphere (ambient pressure) and electrode potential. In situ Raman measurements shown in Figures $2 \mathrm{a}-\mathrm{b}$ and Figure $3 a-b$ in the main text were carried out under a flowing gas (red arrows). The venting valve (valve 1) was switched on before measurements for air extraction. 


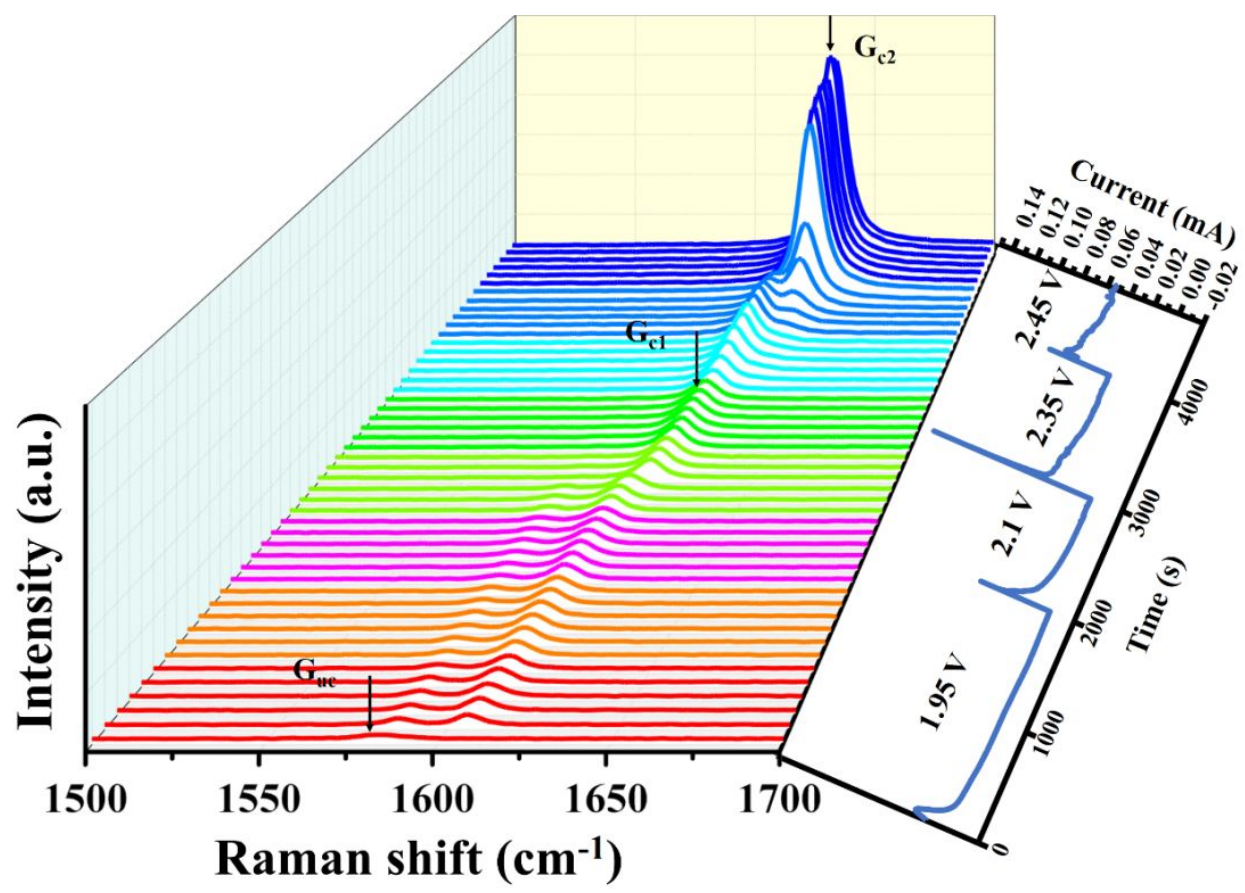

Figure S2. Operando Raman measurements over HOPG electrode upon charging in anhydrous Ar atmosphere. The capture rate of the Raman spectra was $100 \mathrm{~s} / \mathrm{spectrum}$. In order to avoid the interference of electrolyte during charging and the following gastreatment experiments, the Raman laser beams in all operando/in situ Raman measurements were illuminating on the open region of the HOPG electrode in the planar model battery (Figure 1a in the main text). The electrochemical intercalation process was carried out under constant-voltage charging condition which is also displayed on the right. During the charging process, the typical trend of Raman G band can be demonstrated: $\mathrm{G}_{\mathrm{uc}} \rightarrow \mathrm{G}_{\mathrm{uc}}+\mathrm{G}_{\mathrm{c} 1} \rightarrow \mathrm{G}_{\mathrm{c} 1} \rightarrow \mathrm{G}_{\mathrm{c} 1}+\mathrm{G}_{\mathrm{c} 2} \rightarrow \mathrm{G}_{\mathrm{c} 2}$. When $\mathrm{G}_{\mathrm{c} 1}\left(\sim 1620 \mathrm{~cm}^{-1}\right)$ band is dominant, a stage-2 GIC is produced. At the fully charged state, a stage-1 GIC (surface region) can be identified according to the dominant $\mathrm{G}_{\mathrm{c} 2}$ band $\left(\sim 1635 \mathrm{~cm}^{-1}\right)$. $^{3-4}$ The schematics of the stage structures and their corresponding Raman spectra are shown in next figure. 
(a)
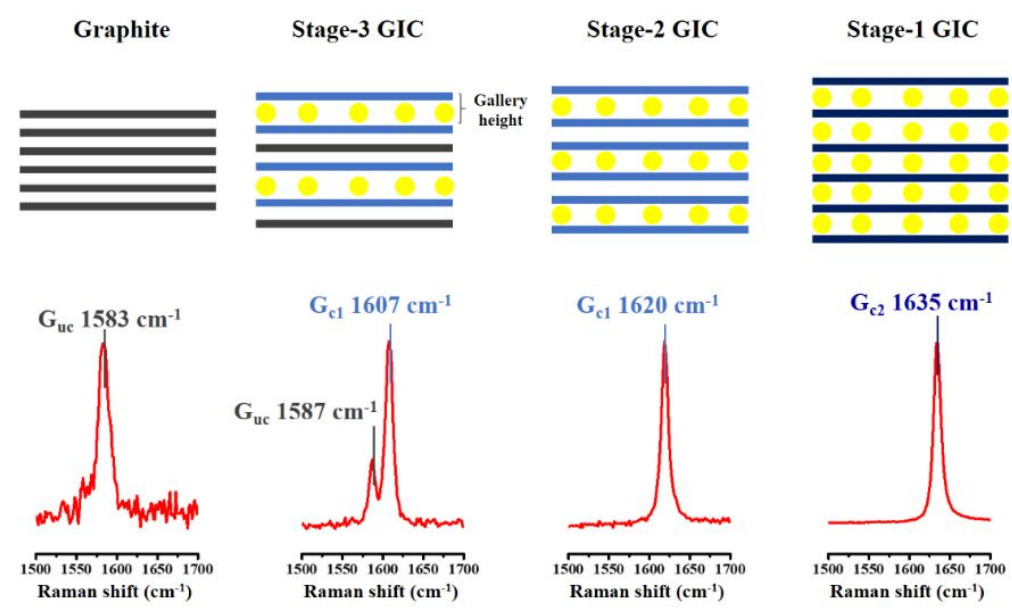

(b)

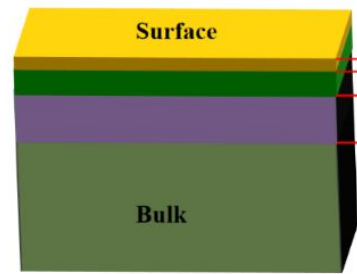

$$
\begin{array}{r|r}
\text { Top most surface region }(\sim 2-3 \mathrm{~nm}): A R X P S\left(700^{\circ}\right) & \text { Surface } \\
\text { Near surface region }(\sim 7-9 \mathrm{~nm}): \text { XPS }) & \\
\text { Surface region }(<100 \mathrm{~nm}): \text { Raman } & \\
\text { Bulk region }(\sim 10 \mathrm{~s} \mu \mathrm{m}): X R D & \\
& \text { Bulk }
\end{array}
$$

Figure S3. (a) Schematics of the GICs with different stage structure and their corresponding Raman spectra. The characteristic Raman G band of the pristine graphite electrode is located at $1583 \mathrm{~cm}^{-1}$ which arises from the in-plane $\mathrm{E}_{2 \mathrm{~g}}$ vibrational mode of $\mathrm{sp}^{2}$ carbons. During charging, the ions tend to intercalate into graphite layers and the GICs with different stage structures can be formed. ${ }^{5}$ The interlayer spacing between two graphene layers with intercalated ions are defined as the gallery height. Commonly, the stage number $n$ of a stage-n GIC can be defined as the number of graphene layers between two adjacent layers of the intercalated ions (a). When stage number $n \geq 3$, the $\mathrm{G}$ band splits up into two peaks. The peak at lower wave number can be assigned to the uncharged graphene (black in (a), denote as $G_{u c}$ ) without neighboring ions while the peak at higher wave number is attributed to the charged graphene (light blue in (a), denote as $\mathrm{G}_{\mathrm{c} 1}$ ) with neighboring ions. ${ }^{6}$ When the stage number $n$ reaches 2 , the $\mathrm{G}_{\mathrm{c} 1}$ band upshifts to $1620 \mathrm{~cm}^{-1}$ and every graphene layer can be charged by the neighboring ions. For stage-1 GIC, the G band upshifts to $1635 \mathrm{~cm}^{-1}$ which can be assigned the charged graphene layers with higher doping level (dark blue in (a), denote as $G_{c 2}$ ). ${ }^{7}$ (b) Schematic of different investigation depth by different characterization methods mentioned in the main text. 


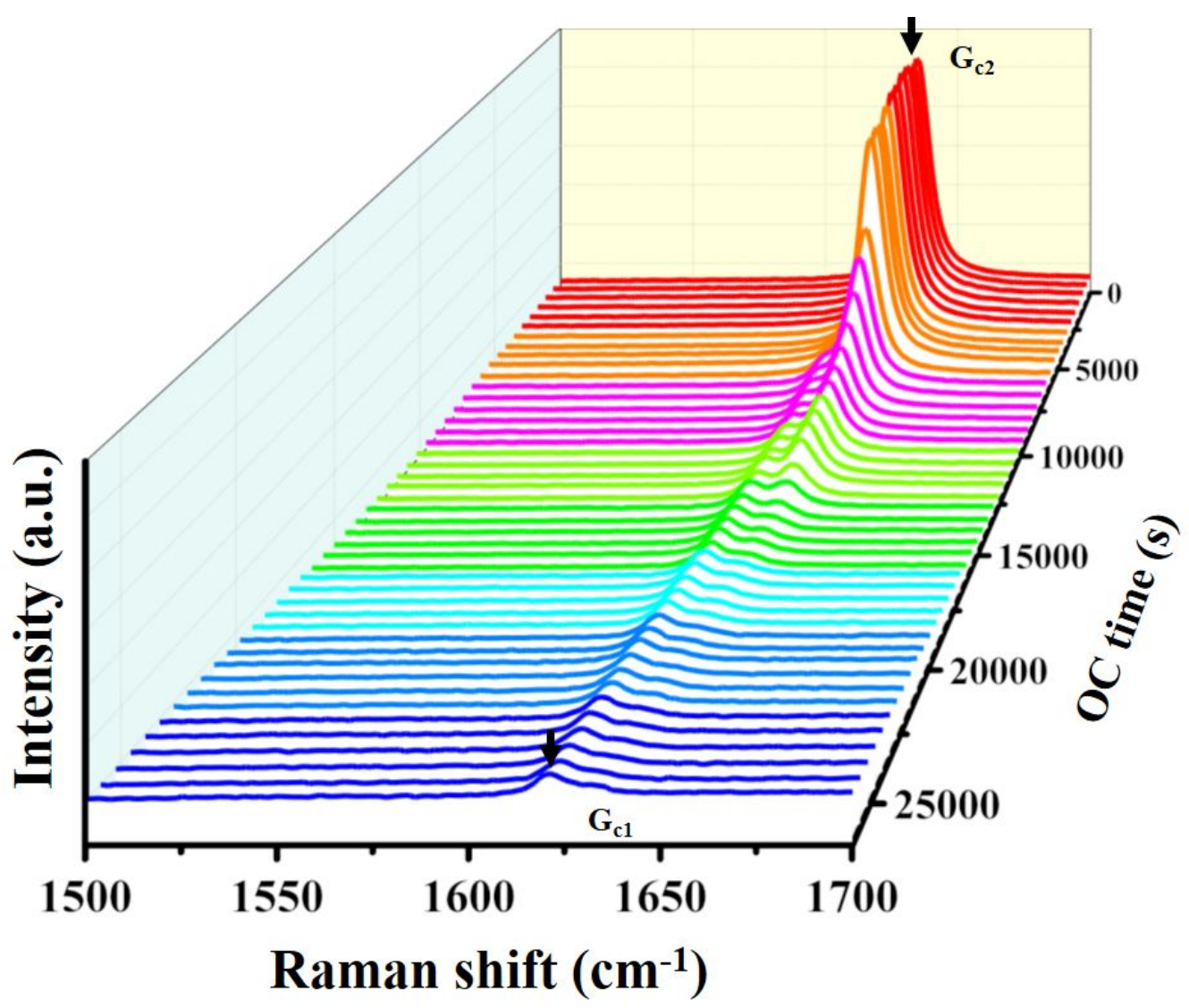

Figure S4. In situ Raman measurements over the as-charged stage-1 (surface region) AIB based GIC under OC condition in anhydrous Ar atmosphere. After the electrochemical intercalation, a stage-1 AIB based GIC is produced with a dominant $\mathrm{G}_{\mathrm{c} 2}$ band located at $\sim 1635 \mathrm{~cm}^{-1}$. The in situ Raman spectra of the relaxation process was carried out in $\mathrm{Ar}$ atmosphere $\left(\mathrm{H}_{2} \mathrm{O}\right.$ and $\left.\mathrm{O}_{2}<0.5 \mathrm{ppm}\right)$. The capture rate of the Raman data was $600 \mathrm{~s}$ per spectrum. As the function of time, the pristine Raman $\mathrm{G}_{\mathrm{c} 2}$ band displayed an asymmetric feature with a shoulder peak $\left(\mathrm{G}_{\mathrm{c} 1}\right)$ located at $\sim 1620 \mathrm{~cm}^{-}$ ${ }^{1}\left(\mathrm{G}_{\mathrm{c} 2} \rightarrow \mathrm{G}_{\mathrm{c} 1}+\mathrm{G}_{\mathrm{c} 2}\right)$. After $26400 \mathrm{~s}$, the $\mathrm{G}_{\mathrm{c} 1}$ band becomes dominant which reveals that a stage-2 $\mathrm{GIC}^{3-4}$ is formed under $\mathrm{OC}$ condition in the surface region. In addition, the Raman intensity keeps decreasing during the OC process. 


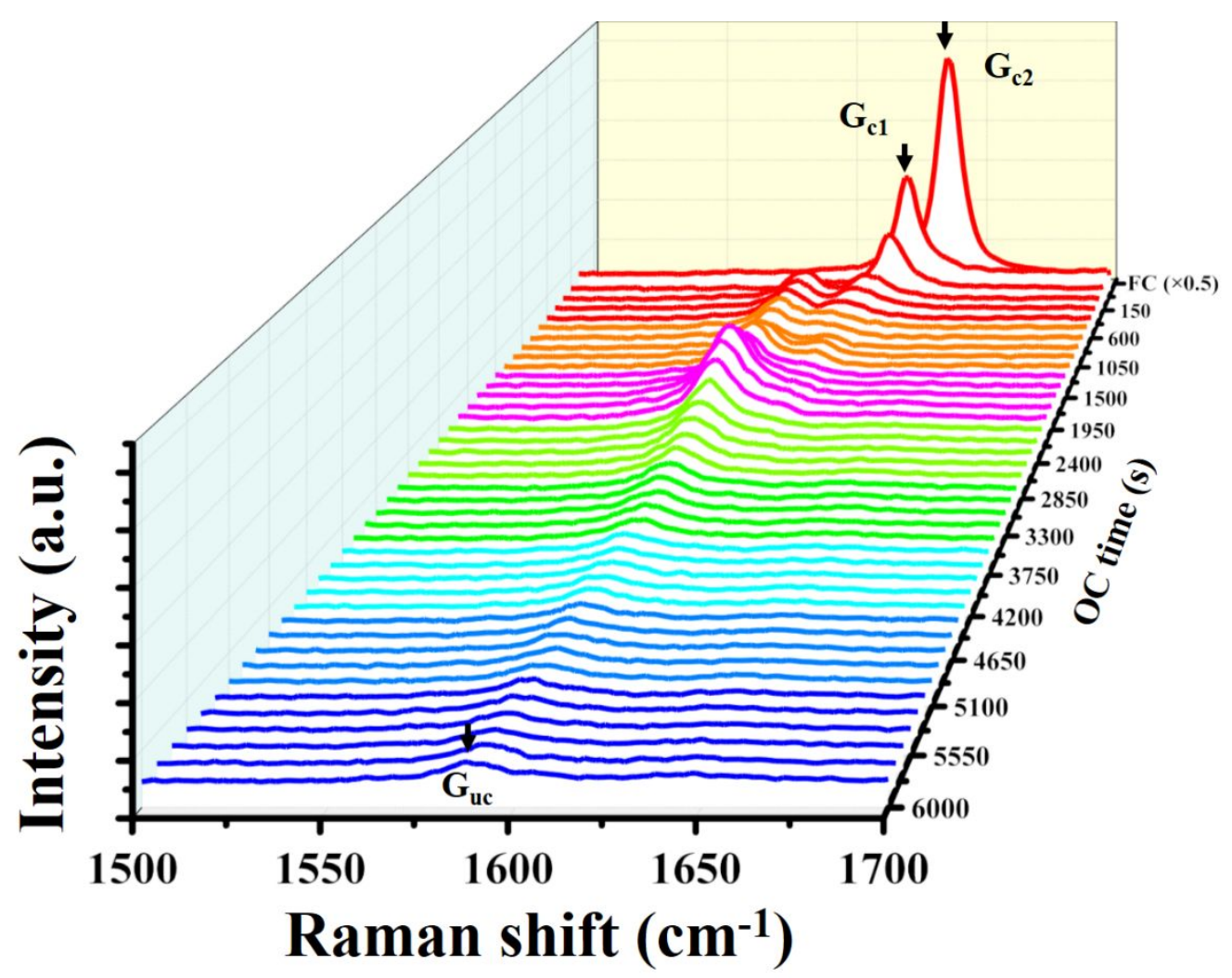

Figure S5. In situ Raman measurements over fully charged (FC) stage-1 AIB based GIC under OC condition after being exposed to Air. The in situ Raman measurements after exposure to air were carried out by disassembling the Raman cell. The capture rate of the Raman data is $150 \mathrm{~s}$ per spectrum. As described in the article, the stage- 1 GIC transforms into stage- 2 directly after being exposed to air. With the exposure time increasing, the ongoing stage-degradation can be observed. After $6000 \mathrm{~s}$, a dominant uncharged graphene layer $\left(G_{u c}\right)$ band with a weak $G_{c 1}$ shoulder peak is observed suggesting that the stage-1 GIC has transformed into a higher stage structure in this case. 
(a)

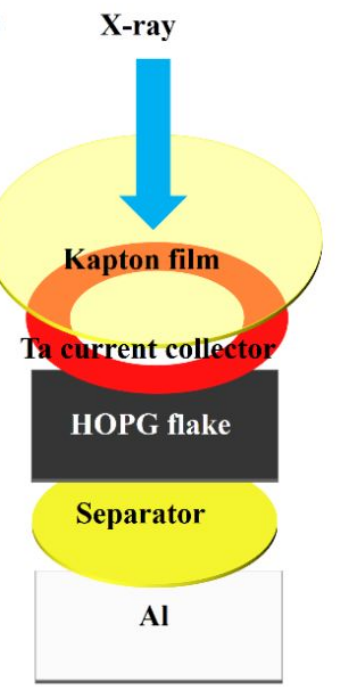

(b)

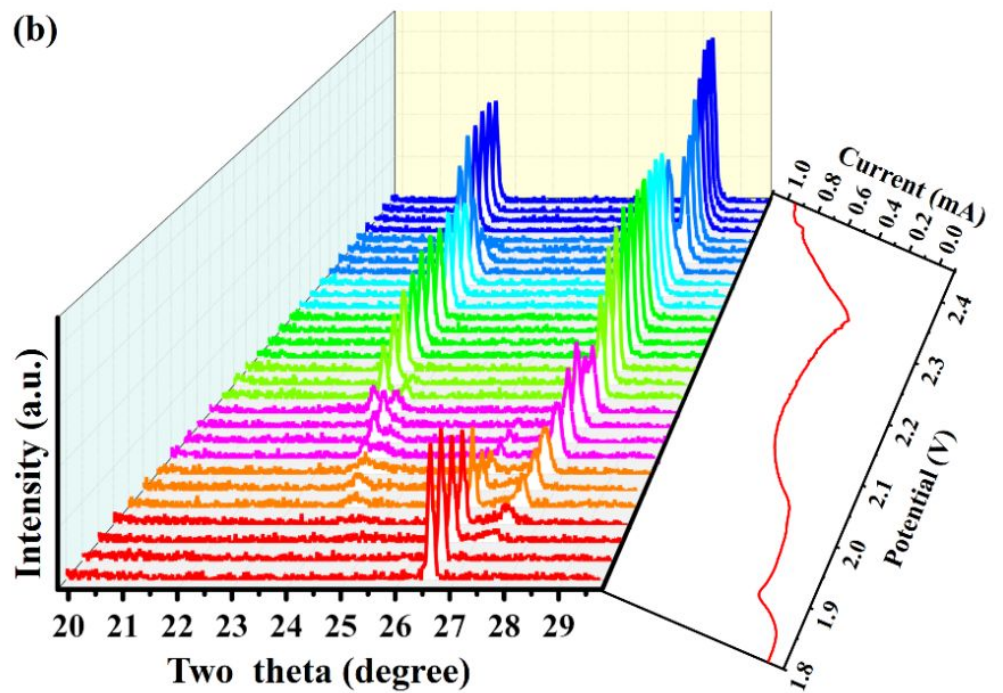

Figure S6. Operando XRD measurements over the HOPG electrode during electrochemical intercalation process. The model batteries in operando XRD measurements were performed with a sandwich configuration (a). The electrochemical intercalation process was carried out under a linear sweep voltammetry (LSV) condition: $1.8-2.45 \mathrm{~V}, 0.1 \mathrm{mV} / \mathrm{s}$. Upon charging, the intensity of pristine HOPG (002) XRD pattern located at $\sim 26.5^{\circ}$ gradually decreases along with two new patterns appearing at higher and lower degrees, respectively. These two new patterns are corresponding to the $(00 n+1)$ and $(00 n+2)$ diffraction peaks of a stage-n GIC. ${ }^{8-10}$

According to Bragg's law, the interplanar spacing of the lattice plane $d$ is calculated by the formula: $2 d \sin \theta=m \lambda$. The interplanar spacing of the $(00 n+1)$ and $(00 n+2)$ lattice plane can be also related to the periodic repeating distance $\mathrm{I}_{\mathrm{C}}$ which are calculated as $\mathrm{I}_{\mathrm{C}} /(\mathrm{n}+1)$ and $\mathrm{I}_{\mathrm{C}} /(\mathrm{n}+2)\left(\mathrm{I}_{\mathrm{C}}=\right.$ gallery height $\left.+3.35 \AA \cdot(\mathrm{n}-1)\right)$. So, the stage number $\mathrm{n}$ can be calculated from the ratio between the interplanar spacing of $(00 n+1)$ and $(00 n+2)$ lattice plane from the XRD patterns: $d_{n+1} / d_{n+2}=(n+2) /(n+1)$. At fully charged state $(2.45$ V), two diffraction peaks located at $22.5^{\circ}$ and $28.3^{\circ}$ are found. The stage number of fully charged GIC can be calculated as 3 and the gallery height of intercalant within two graphene layers can be calculated as $9.1 \AA$. 


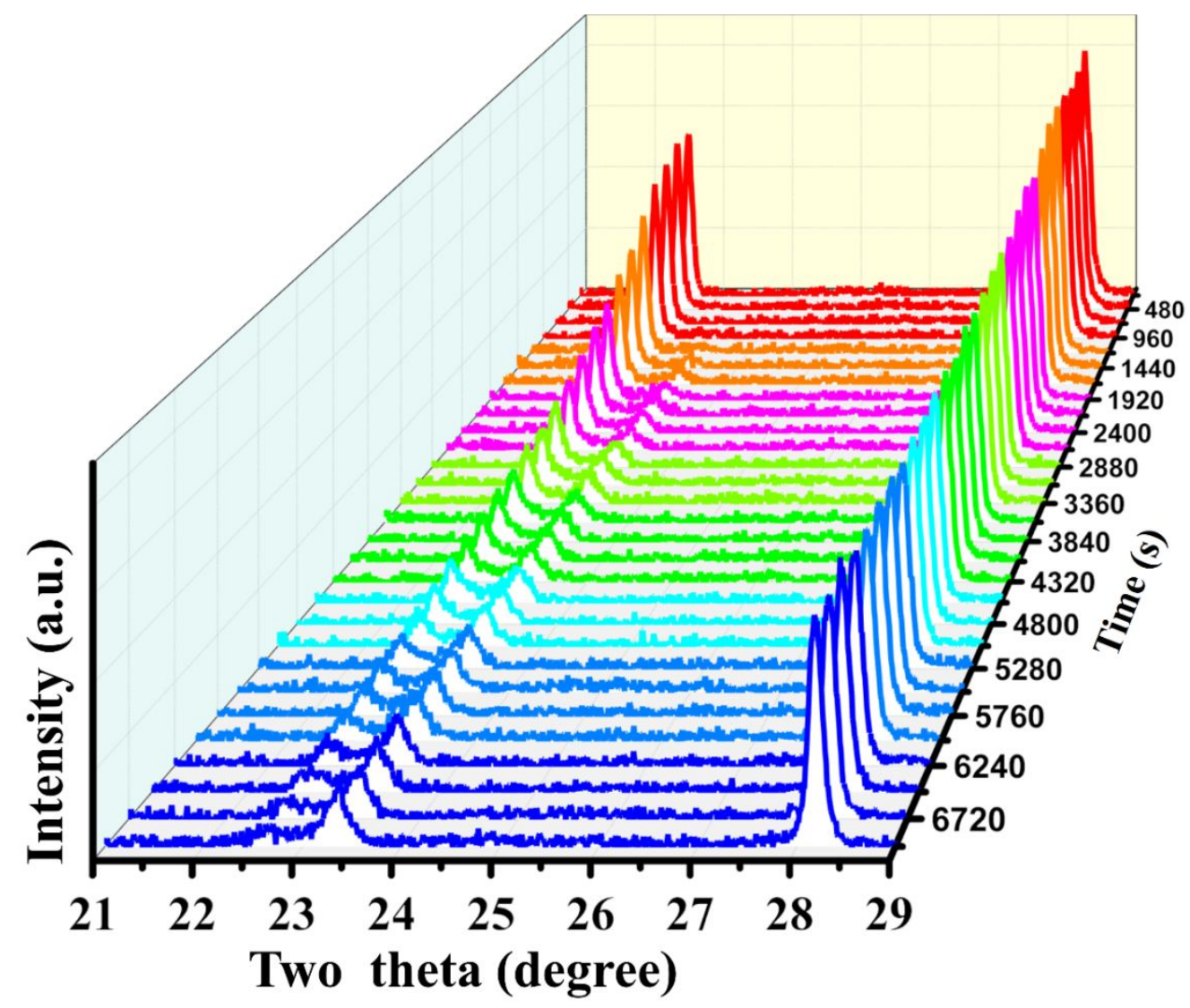

Figure S7. In situ XRD measurements over the as charged GIC (stage-3 in bulk) in hydrous Ar atmosphere under OC condition. After the electrochemical intercalation, a stage-3 (bulk region) AIB based GIC is produced with a dominant (004) and (005) diffraction peaks located at $22.5^{\circ}$ and $28.3^{\circ}$, respectively. Like the Raman results, in Ar atmosphere $\left(\mathrm{H}_{2} \mathrm{O}, \mathrm{O}_{2}<0.5 \mathrm{ppm}\right)$ a newly appeared $(00 \mathrm{n}+1)$ diffraction peak at $23.4^{\circ}$ is found and gradually becomes dominant. Simultaneously, the $(00 n+2)$ diffraction peak gradually shifts from $28.3^{\circ}$ to $28.2^{\circ}$ as the function of time. In this case, the stage number $\mathrm{n}$ is calculated as 4 and gallery height is about $9.0 \AA$ (Figure 1f). The capture rate of the all the in situ XRD pattern is $240 \mathrm{~s} /$ spectrum. 


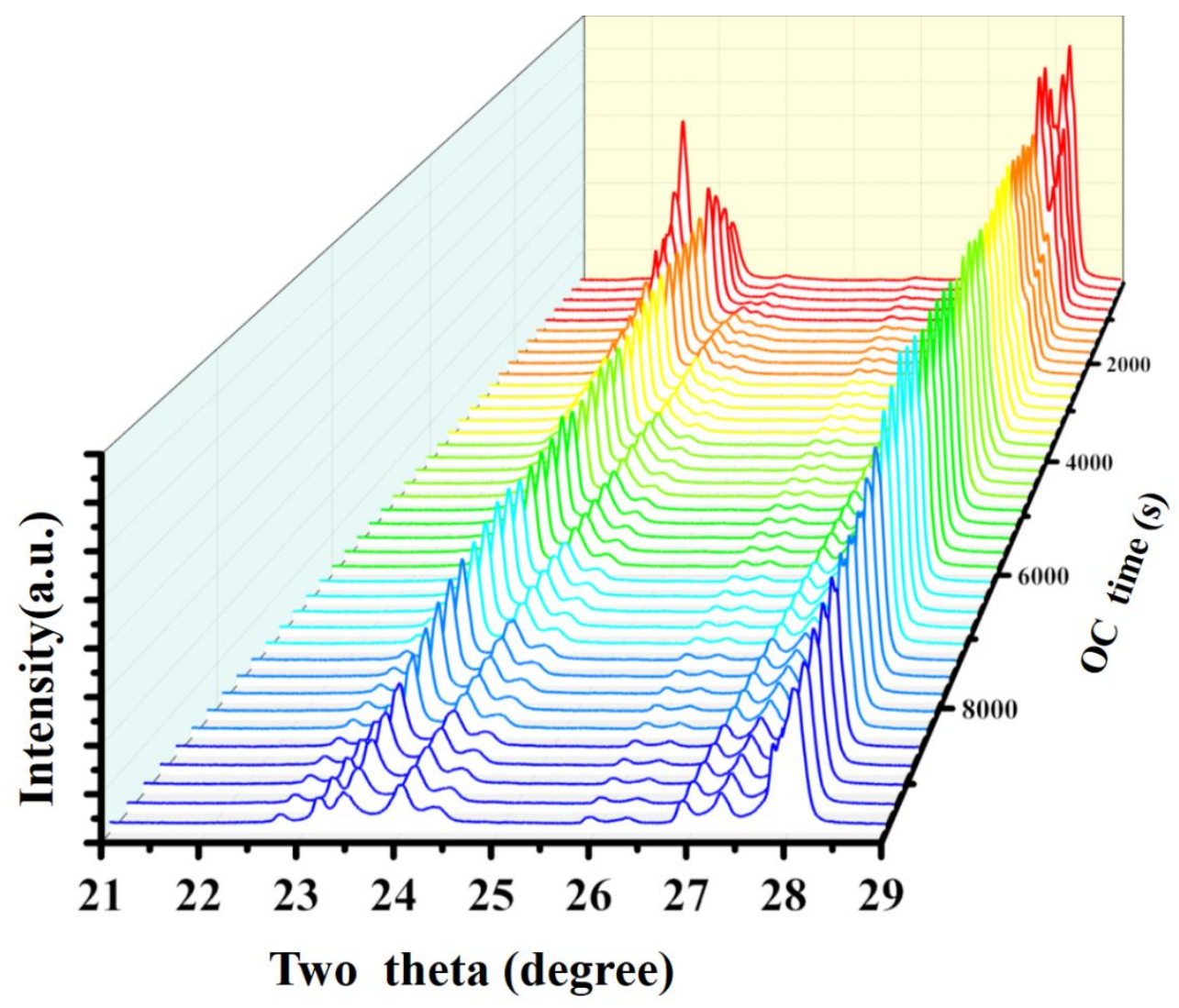

Figure S8. In situ XRD measurements over the as-charged GIC electrode after being exposed to air. Like Raman measurements, the in situ XRD measurements over the electrode after exposure to air were carried out by disassembling the in situ XRD cell. After exposure to air, several new groups of the diffraction peaks can be observed revealing that a mixture of multiple stage structures are formed. The detail information is displayed in next figure and Table S1. 


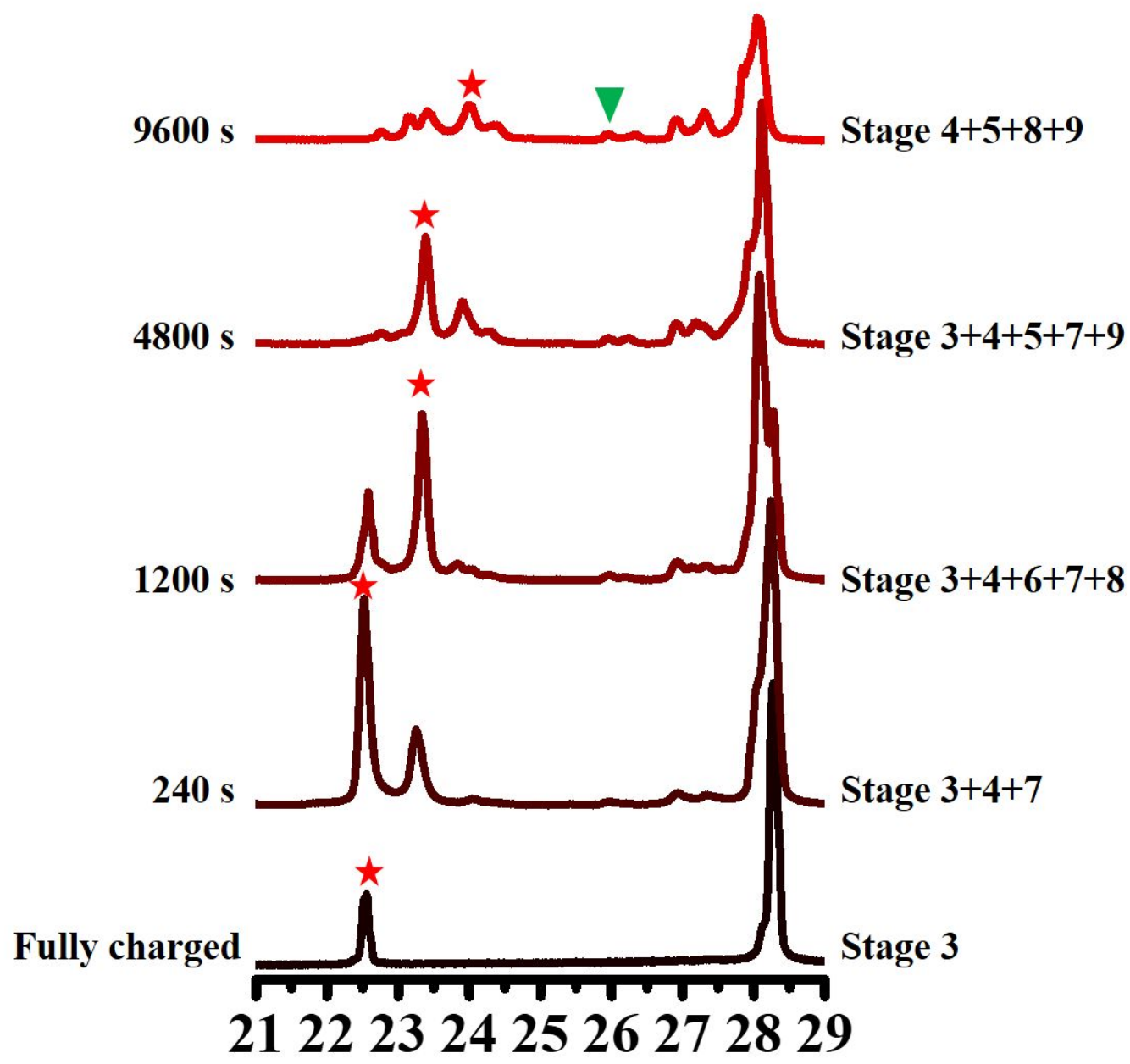

Figure S9. Selected XRD patterns of the GIC electrode after being exposed to air (from Figure S8). The stage number is identified by the groups of $(00 n+1)$ and $(00 n+2)$ diffraction peaks. Specially, a single peak at $\sim 26^{\circ}$ has been discovered (marked by green triangle) which can be assigned to the expanded graphene layer whose interlayer spacing is $\sim 3.4 \AA$. So, there exists severe structural degradation and distortion after being exposed to air. The strongest $(00 n+1)$ diffraction peaks mentioned in Fig. 1 are marked by red stars. 
Table S1. Summary of the dominant $(00 n+1)$ and $(00 n+2)$ diffraction peaks, stage number, and gallery height of the selected XRD patterns in Figure S9.

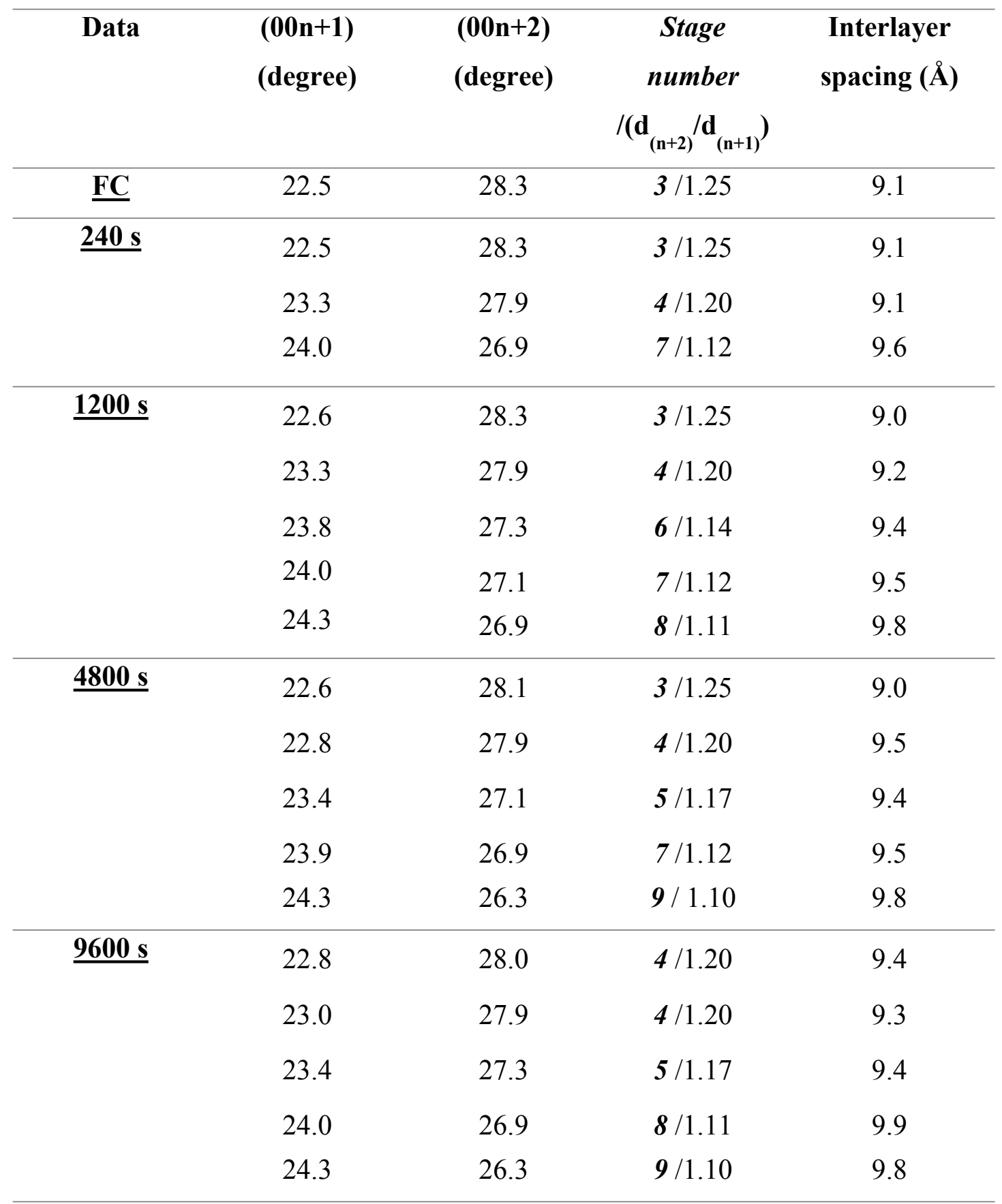




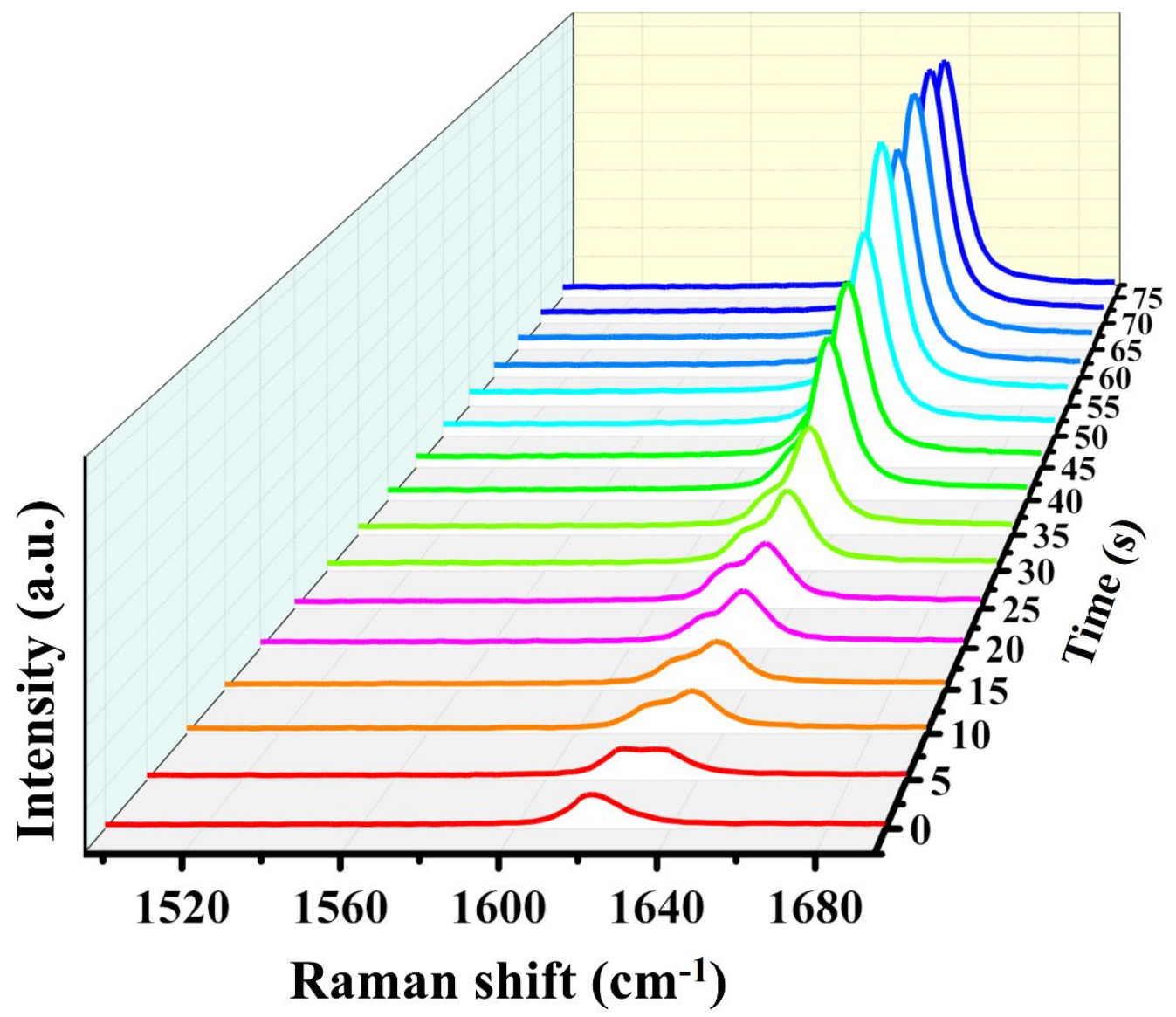

Figure S10. Operando Raman measurements over the as-relaxed GIC electrode (stage2 ) in the recharging process. The recharging process are carried out by directly applying the charging voltage $(2.45 \mathrm{~V})$ after the relaxation process. The capture rate of the Raman data was $5 \mathrm{~s}$ per spectrum. After applying the potential, rapid and inverse changes of $G$ band and stage structure can be found: $\mathrm{G}_{\mathrm{c} 1}$ (stage-2) $\rightarrow \mathrm{G}_{\mathrm{c} 1}+\mathrm{G}_{\mathrm{c} 2}$ (stage$1+2) \rightarrow \mathrm{G}_{\mathrm{c} 2}$ (stage-1). 


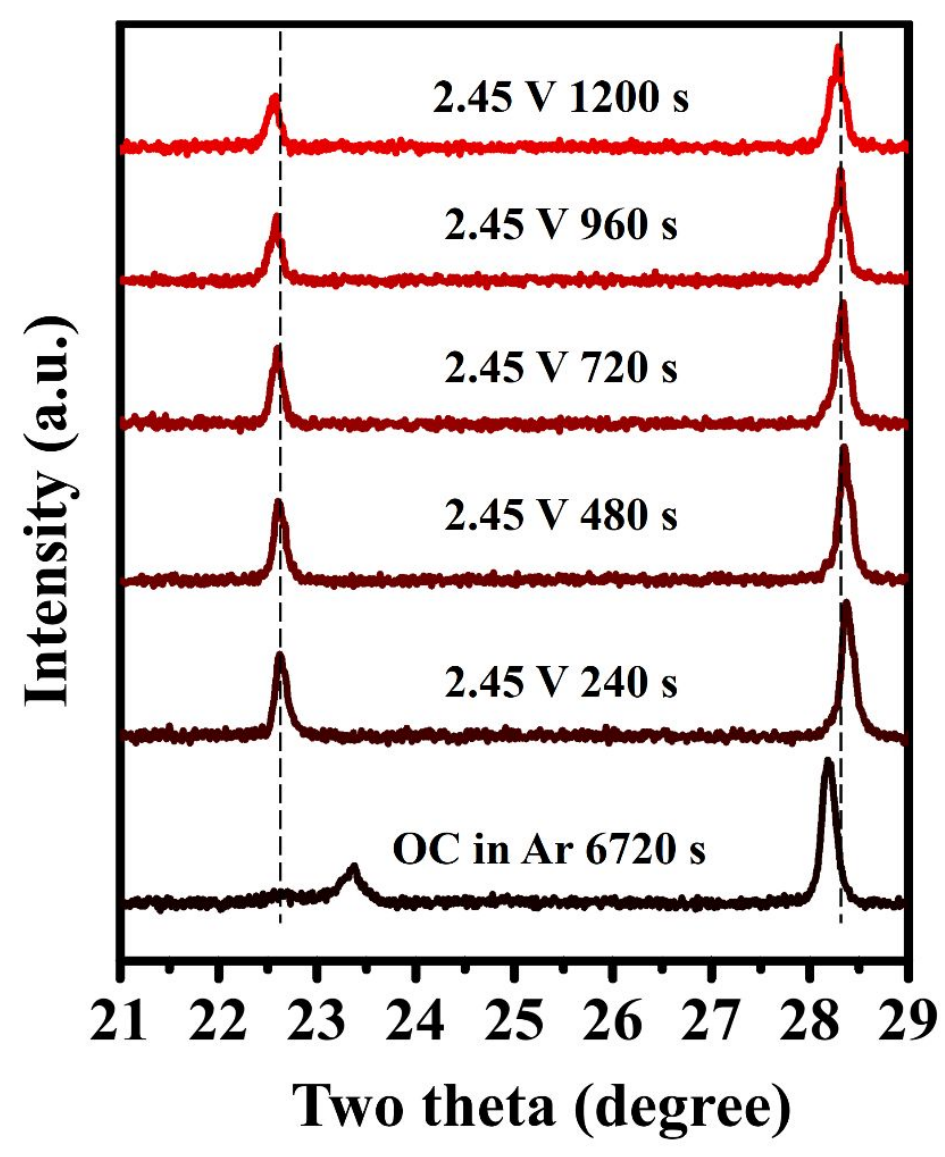

Figure S11. Operando XRD measurements over the as-relaxed GIC electrode in the recharging process. Same as Raman, the recharging processes are carried out by directly applying the charging voltage $(2.45 \mathrm{~V})$ after the relaxation process. The stage-4 GIC after the relaxation transforms into a stage-3 intercalation structure once the potential was applied. 


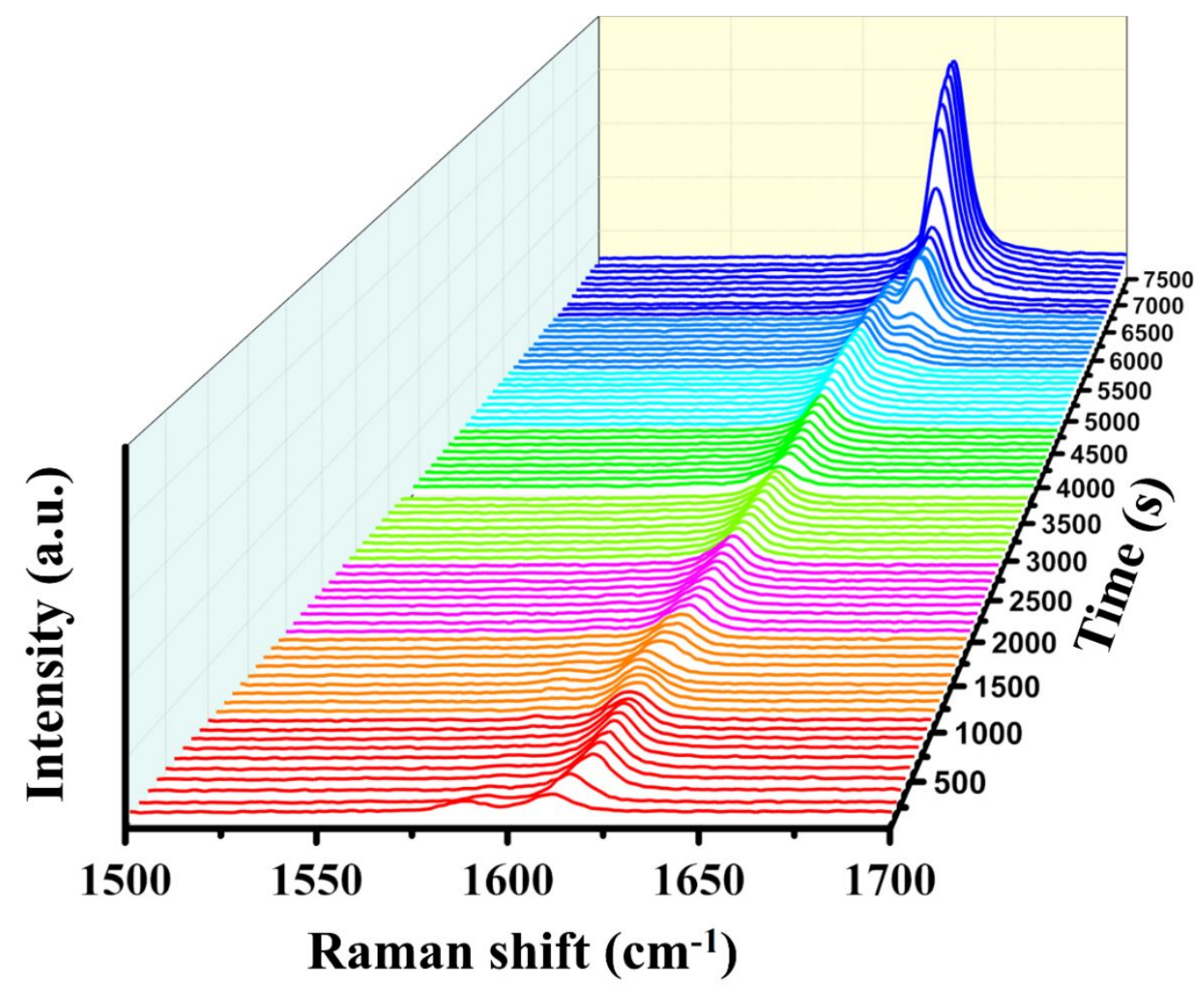

Figure S12. Operando Raman measurements over the GIC electrode after being exposed to air in re-intercalation process. In order to remove the water, the GIC electrode after being exposed to air was dried $\left(\sim 80{ }^{\circ} \mathrm{C}\right.$ in vacuum for $\left.1 \mathrm{~h}\right)$ before resembling the battery with fresh IL electrode and Al foil. The charging voltage in this case is also $2.45 \mathrm{~V}$. It can be found that the electrode can also be charged under this condition. After charging for $2 \mathrm{~h}$, the stage-4 GIC (after drying) transforms into a stage1 GIC. Capture rate of the Raman spectra: $100 \mathrm{~s} / \mathrm{spectrum}$. 


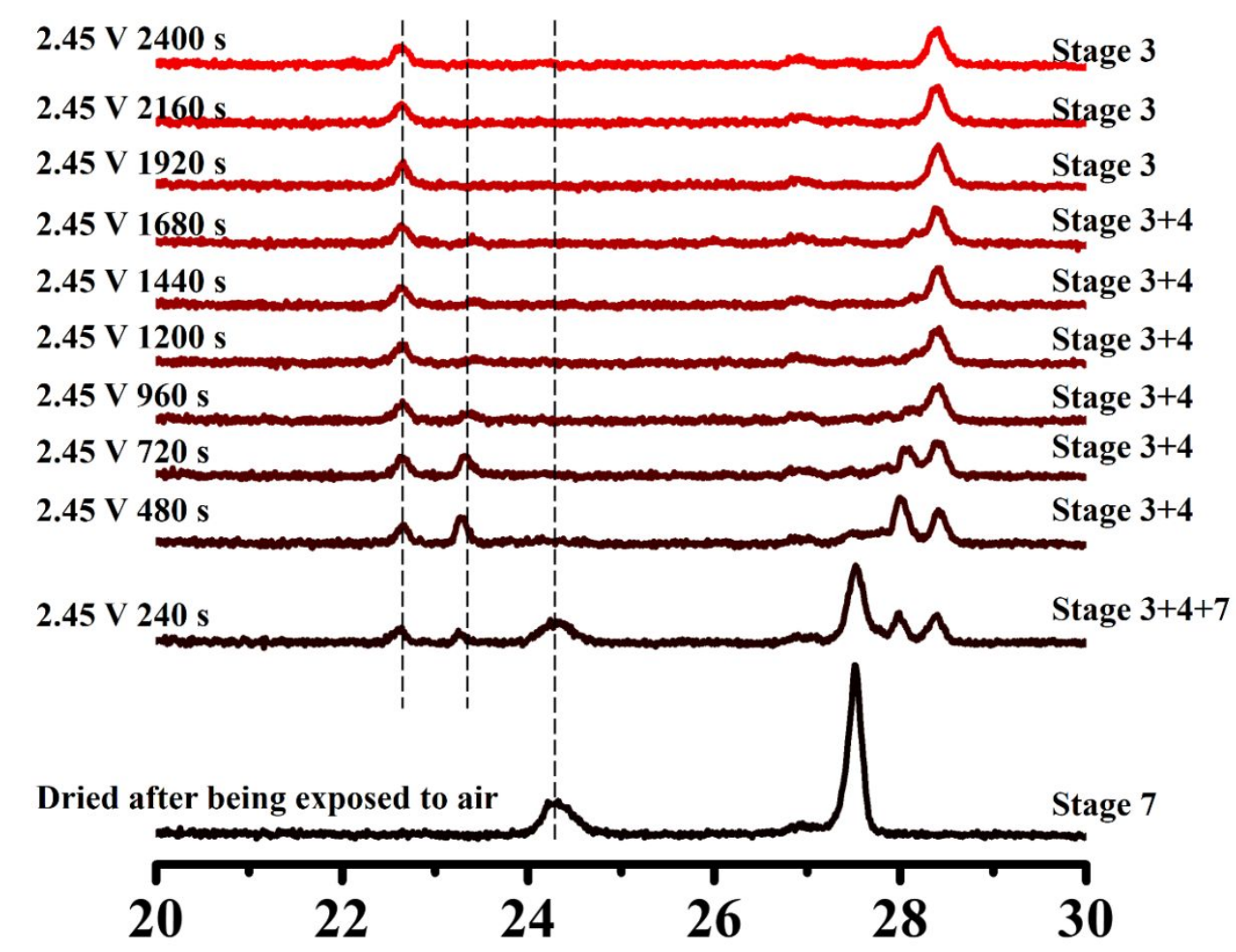

Figure S13. Operando XRD measurements over the electrode after being exposed to air in the re-intercalation process. After being dried $\left(80^{\circ} \mathrm{C}\right.$ in vacuum), the stage number of GIC electrode after exposure to air can be calculated as 7. The charging potential $(2.45 \mathrm{~V})$ was applied onto the battery which was resembled with fresh IL and Al foil. The newly appeared diffraction patterns can be assigned as the characteristic of the stage-3 and stage-4 GIC. After 2400 s, a stage-3 GIC is produced. 


\section{Supplementary XPS data}

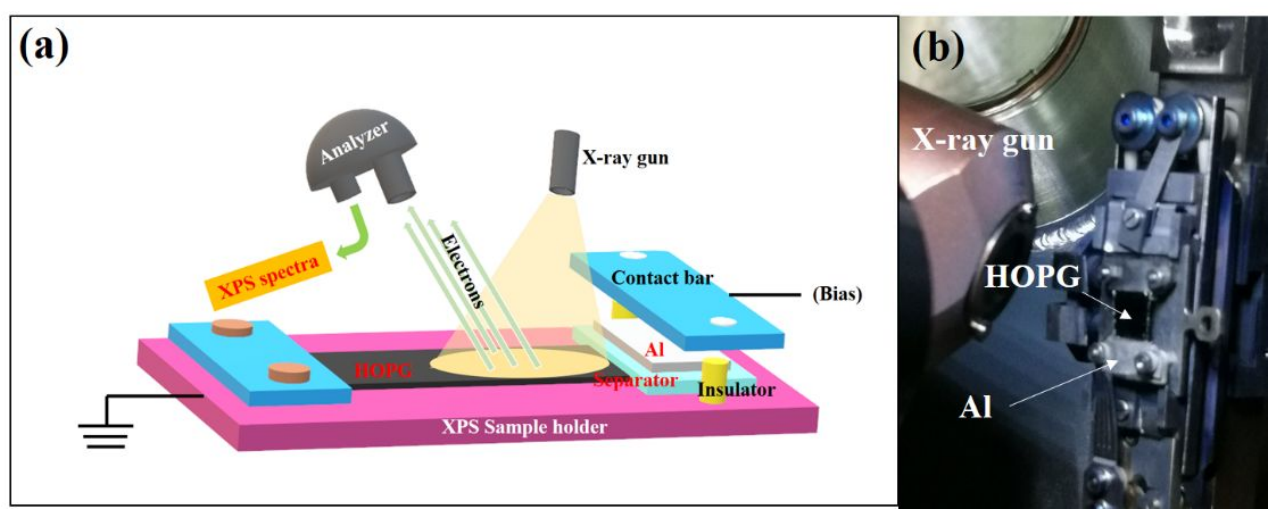

Figure S14. (a) Schematic and (b) photo of Al | IL | HOPG model battery used for operando/in situ XPS measurements. The battery is mounted onto an Omicron-type direct-current heating sample holder. The HOPG flake cathode is always grounded during charging processes and XPS measurements, while the bias is applied to the Al anode via the contact bar. ${ }^{2}$ 
(a)

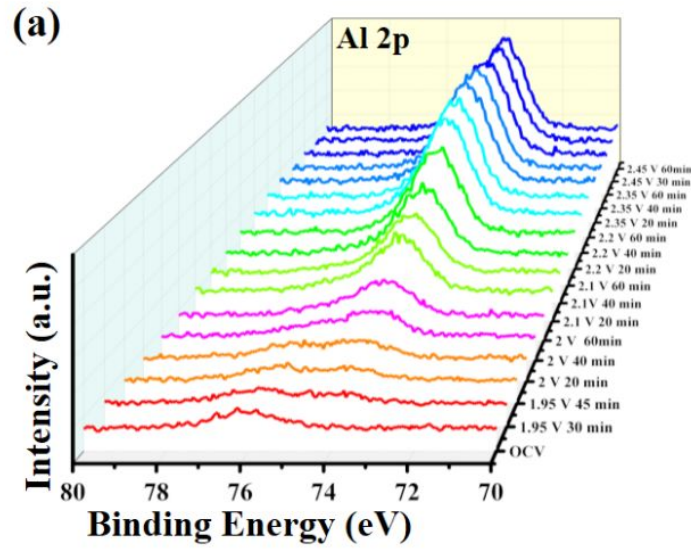

(c)

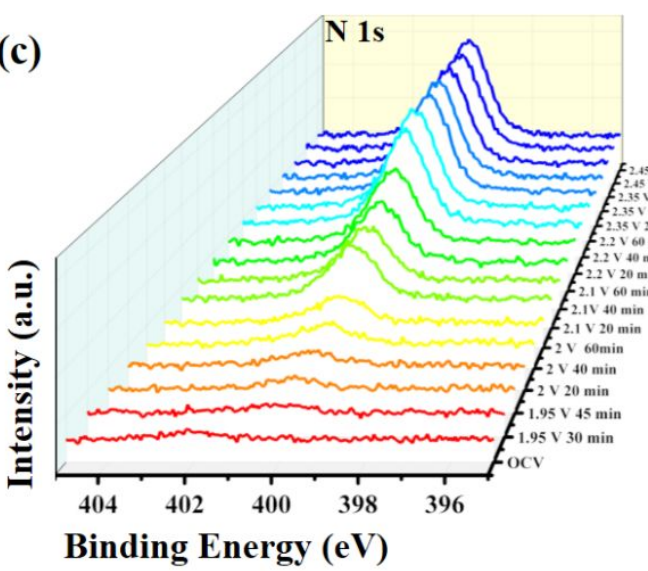

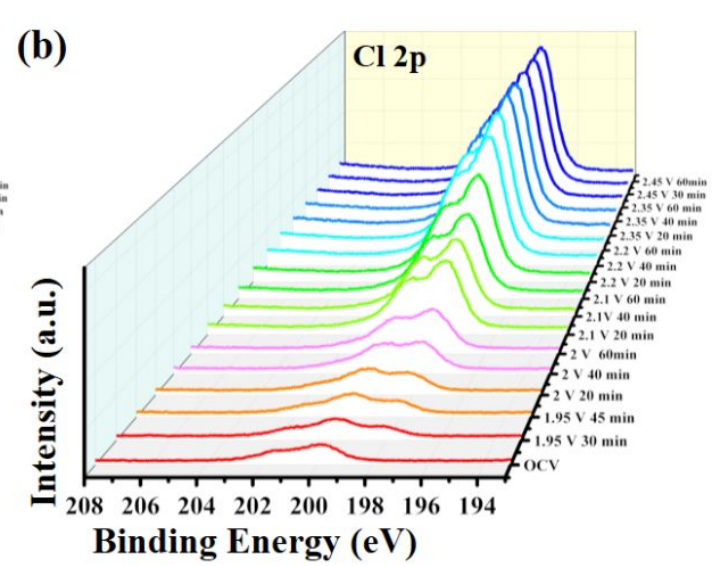

(d)

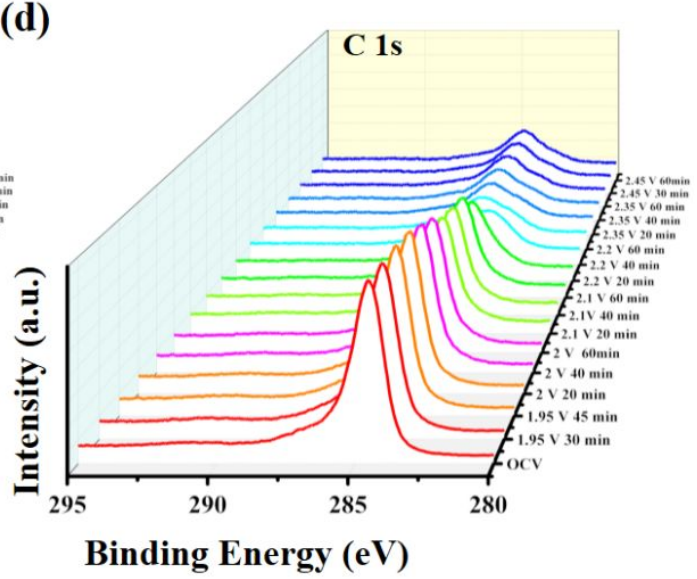

Figure S15. Operando XPS measurements (UHV) over the HOPG electrode during charging process. The intercalant-related XPS signals: (a) Al 2p; (b) $\mathrm{Cl} 2 \mathrm{p}$ and (c) N 1s signals are all obviously increasing during charging while the intensities of $\mathrm{C} 1 \mathrm{~s}(\mathrm{~d})$ are strongly weakened due to the remarkable volume expansion. The BEs of the intercalation species are $\sim 1.7 \mathrm{eV}$ lower than OCV state (first spectrum) which corresponds to the work function evolution. The super dense co-intercalation charging mechanisms in surface region can be well demonstrated by the operando XPS measurements which have been discussed in detail in our previous work. ${ }^{2}$ 

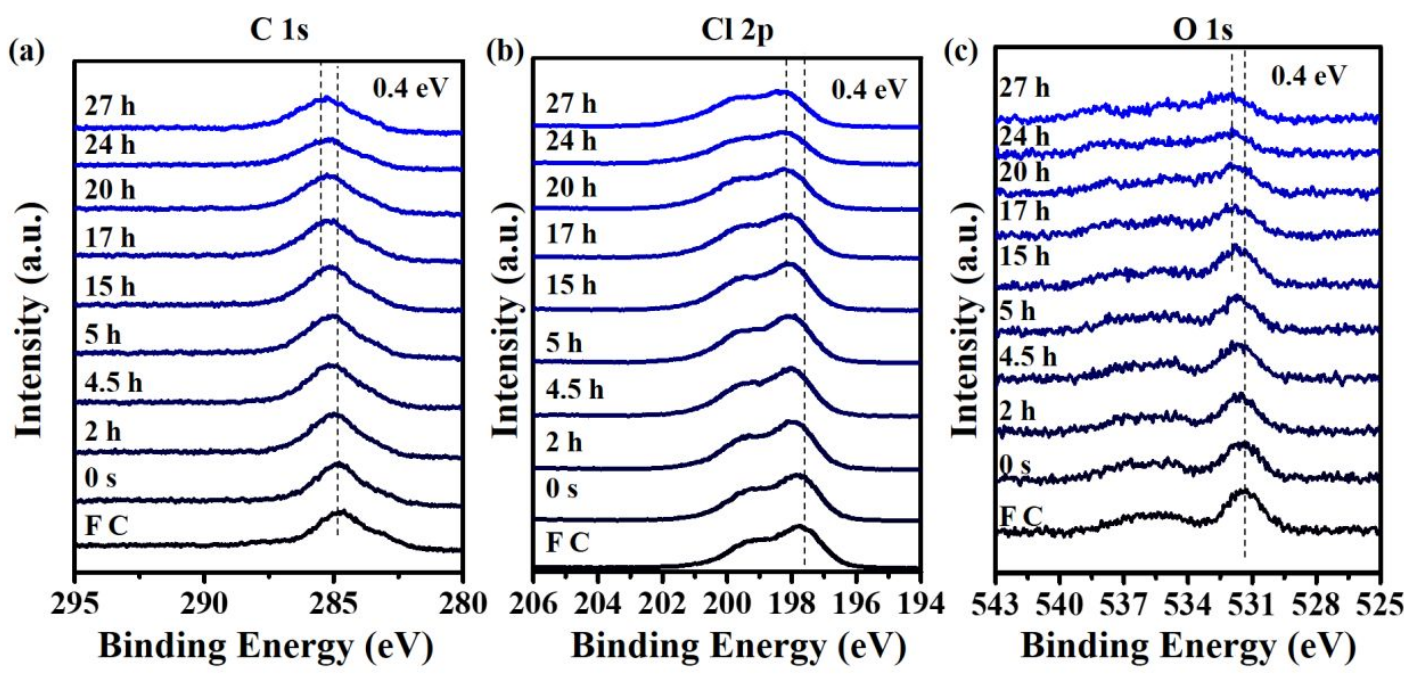

Figure S16. In situ XPS C 1s (a), Cl 2p (b) and O 1s (c) signals of the as-charged electrode in UHV under OC conditions. As analogous to Al $2 \mathrm{p}$ and $\mathrm{N} 1 \mathrm{~s}$ shown in Fig. $2 \mathrm{~d}$ and e in main text, all spectra including $\mathrm{N} 1 \mathrm{~s}, \mathrm{Cl} 2 \mathrm{p}$ and $(\mathrm{C}-\mathrm{N})$ int in $\mathrm{C} 1 \mathrm{~s}$ present a shift of $+0.4 \mathrm{eV} \mathrm{BE}$ after OC for $27 \mathrm{~h}$ in UHV condition. 

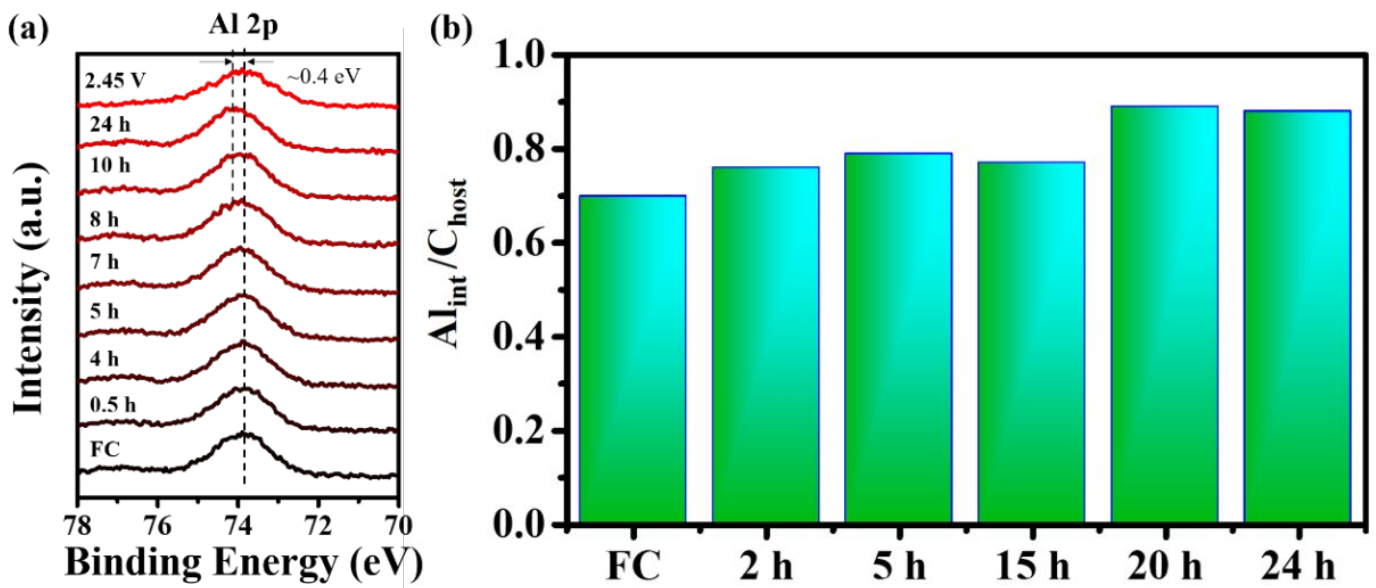

Figure S17. (a) A set of Al 2p XPS signals of the as-charged electrode in UHV under OC conditions for different periods and after applying the charging potential $(2.45 \mathrm{~V})$. The BE can be recovered once the charging potential was applied. (b) Atomic ratios between intercalated $\mathrm{Al}$ (Alint) and host $\mathrm{C}$ (Chost) at different times according to the XPS results. In line with our previous work, during OC process the $\mathrm{Al}_{\text {int }} / \mathrm{C}_{\text {host }}$ ratio increases slightly $^{2}$. As described in the article, such results confirm that the de-intercalation of the ions is not involved. Our in situ Raman measurements confirm the thermodynamically driven stage-relaxation from stage-1 to stage-2 during OC. As illustrated in Figure 4a, such phase transformation can further slightly attenuate the C 1s signal and cause the increase of $\mathrm{Al}_{\text {int }} / \mathrm{C}_{\text {host }}$ in this case. 

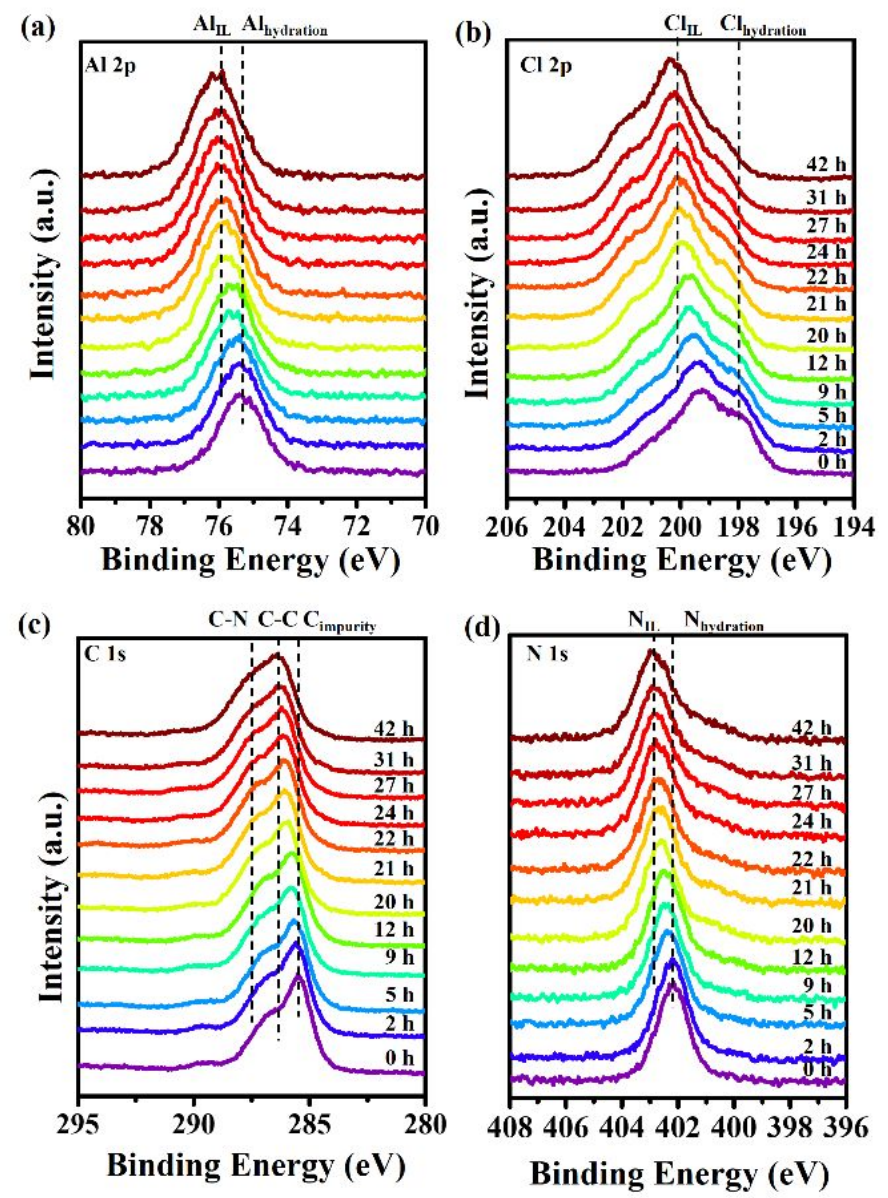

Figure S18. XPS signals of Al 2p (a), Cl 2p (b), C 1s (c) and N 1s (d) of the IL droplet $\left(\mathrm{AlCl}_{3}-\mathrm{EMICl}(1.3: 1\right.$ by mole)$)$ acquired under UHV condition at different periods. Upon storage in UHV ( $\mathrm{P}<2 \times 10^{-9}$ mar), the XPS signals attributed to the surface adsorbed species such as $\mathrm{H}_{2} \mathrm{O}$ (and corresponding hydration species) and some organic impurities gradually decrease. Meanwhile, the XPS signals of the IL become dominant. Therefore, the observed BE shift can be attributed to the evaporation of the volatile $\mathrm{H}_{2} \mathrm{O}$ /impurities adsorbed on the surface and the change of the charging state. ${ }^{1-12}$ Overall, the IL is quite stable under UHV condition due to its extremely low vapor pressure. 

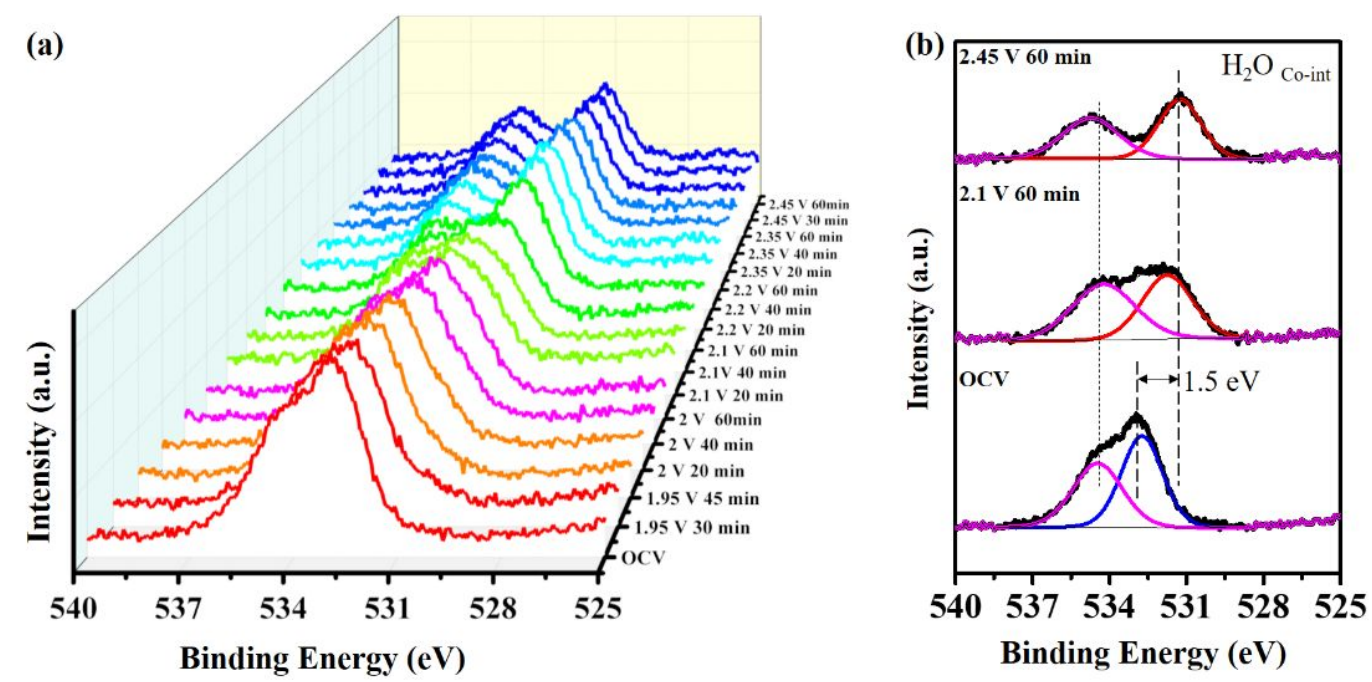

Figure S19. Operando XPS O 1s signals of the HOPG electrode during charging process. Each spectrum (a) was recorded under the same charging condition shown in Figure S15. During charging O 1s intensities are almost consistent, and the pristine broad O 1s band at OCV state gradually splits into two sharp peaks located at higher and lower BEs. Theoretically, the source of O element in OCV state can be contributed to two aspects: (i) some $\mathrm{C}-\mathrm{O}_{\mathrm{x}}$ functional groups on the $\mathrm{HOPG}$ surface; (ii) slight $\mathrm{H}_{2} \mathrm{O}$ in electrolyte which is produced by the reaction between acid IL electrolyte and aluminum oxide films on $\mathrm{Al}$ anode. ${ }^{13-15}$ During charging, the $\mathrm{C}-\mathrm{O}$ groups are oxidized and thus its BE shifts toward higher positions (pink line in (b)). While the $\mathrm{O} 1 \mathrm{~s}$ at lower BE part is attributed to the $\mathrm{H}_{2} \mathrm{O}$ in electrolyte (blue line in (b)). During charging, $\mathrm{H}_{2} \mathrm{O}$ can co-intercalate with $\mathrm{AlCl}_{4}$ and its $\mathrm{BE}$ position is lower (red lines in (b)) similar with the other intercalation species shown in Figure S15. At the fully charged state, the $\mathrm{O} 1 \mathrm{~s}$ BE attributed to the co-intercalated $\mathrm{H}_{2} \mathrm{O}$ is $\sim 1.5 \mathrm{eV}$ lower than the OCV state. After exposure to $\mathrm{H}_{2} \mathrm{O}$, the intensity of $\mathrm{O} 1 \mathrm{~s}$ at the lower BE (Fig. 3e) increases obviously which further prove that the $\mathrm{O} 1 \mathrm{~s}$ in lower BE part is attributed to the $\mathrm{H}_{2} \mathrm{O}$. 


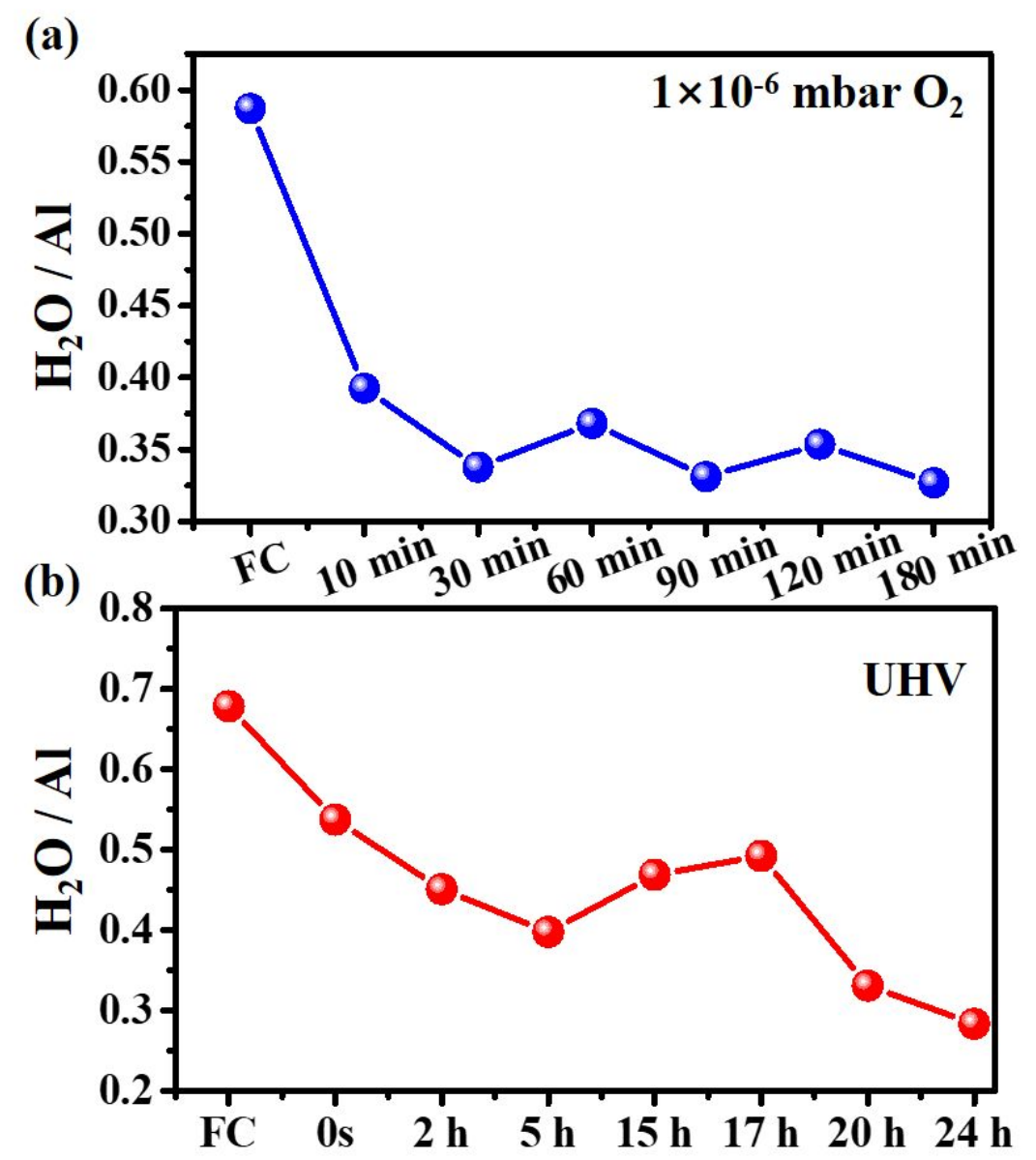

Figure S20. The ratios between $\mathrm{H}_{2} \mathrm{O}$ (lower $\mathrm{BE}$ part of $\mathrm{O} 1 \mathrm{~s}$ ) and $\mathrm{Al}$ at fully charged (FC) state and after OC in $1 \times 10^{-6} \mathrm{mbar}_{2}$ (a) or UHV (b) according to the in situ XPS measurements shown in Figure 2. It can be concluded that the influence of external $\mathrm{H}_{2} \mathrm{O}$ is not involved both in UHV and $\mathrm{O}_{2}$ treatment. On the contrary, the ratios between $\mathrm{H}_{2} \mathrm{O}$ and $\mathrm{O}_{2}$ under these cases are both decreasing. As discussed in the $\mathrm{H}_{2} \mathrm{O}$ treatment section, the amount and distribution of intercalated $\mathrm{H}_{2} \mathrm{O}$ have strong effects on the electronic structure. So, under UHV or low pressure $\mathrm{O}_{2}$, the electronic structure evolution is not only due to the anion/cation redistribution but the distribution of $\mathrm{H}_{2} \mathrm{O}$. Considering the rapid and sharp reduction after being exposed to $\mathrm{O}_{2}$, the $\mathrm{O}_{2}$-promoted redistribution of anion/cation and $\mathrm{H}_{2} \mathrm{O}$ can be demonstrated. 

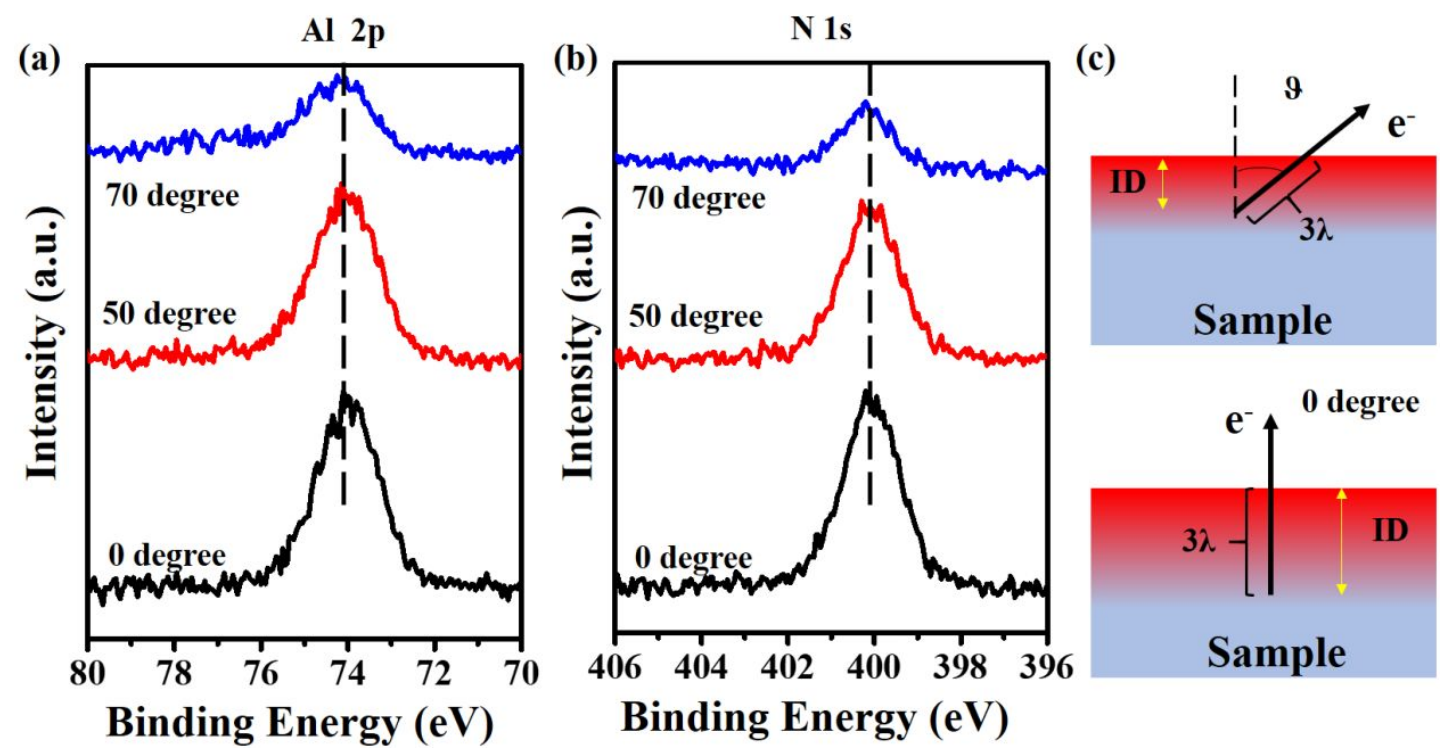

Figure S21. Angle-resolved XPS (ARXPS) Al 2p (a) and N 1s (b) signals at fully charged state. As illustrated in (c), the information depth (ID) in ARXPS can be defined as $3 \cdot \lambda \cdot \cos (\vartheta) \cdot \lambda$ is the inelastic mean free path of the photoelectron whose typical value is 2-3 $\mathrm{nm}$. Therefore, the depth-dependent chemical information can be obtained by altering the photoelectron emission angle $(\vartheta)$ i.e., the angle between the normal of sample and analyzer. For conventional XPS measurements, the emission angle $\vartheta=0^{\circ}$ and the ID can be estimated as $6-9 \mathrm{~nm}$. As for $\vartheta=70^{\circ}$, ID is reduced to $2-3 \mathrm{~nm}$ which can measure the topmost surface region ${ }^{16}$. As illustrated in our previous work ${ }^{2}$, the charging mechanism in the surface region is a super-dense multilayer intercalation mode. ARXPS in this case $\left(\vartheta=70^{\circ}\right)$ can reflect the ions adjoining the topmost graphene layer. During ARXPS measurements, the external charging potential $(2.45 \mathrm{~V})$ was maintained. At the fully charged state, the electronic structure is always consistent from the topmost surface region to the surface region considering that the BEs are the same. 


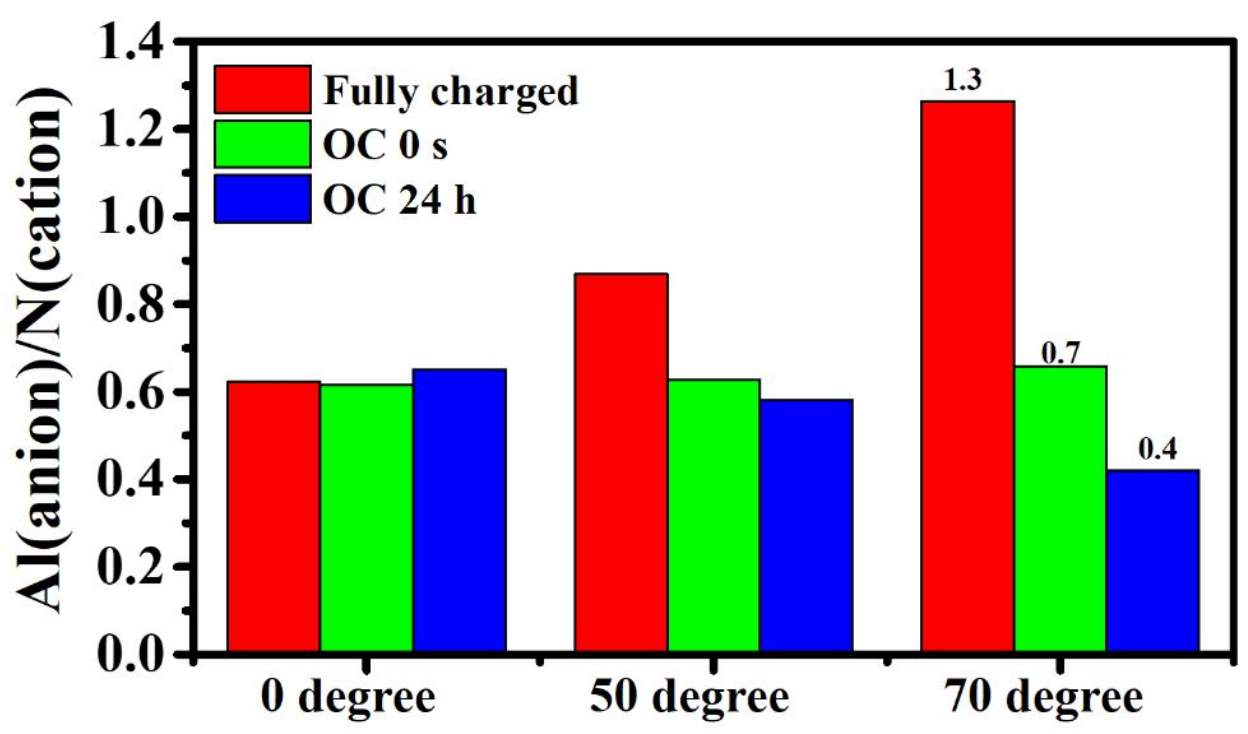

Figure S22. The atomic ratio between $\mathrm{Al}$ (in anion) and N (in cation) at fully charged (FC) state; OC $0 \mathrm{~s}$ (after remove the bias) and OC for $24 \mathrm{~h}$ in UHV according to the ARXPS results (shown in Figure S23). As discussed above, the positive BE shift can be discovered once the bias is removed ( $\mathrm{OC} 0 \mathrm{~s}$ ) in the topmost surface region. Accordingly, the atomic ratio in this case decreases from 1.3 (FC) to 0.7. After OC for $24 \mathrm{~h}$, the ratio $\mathrm{Al} / \mathrm{N}$ decreases to 0.4 . Such results can well demonstrate the charge redistribution process during OC. 

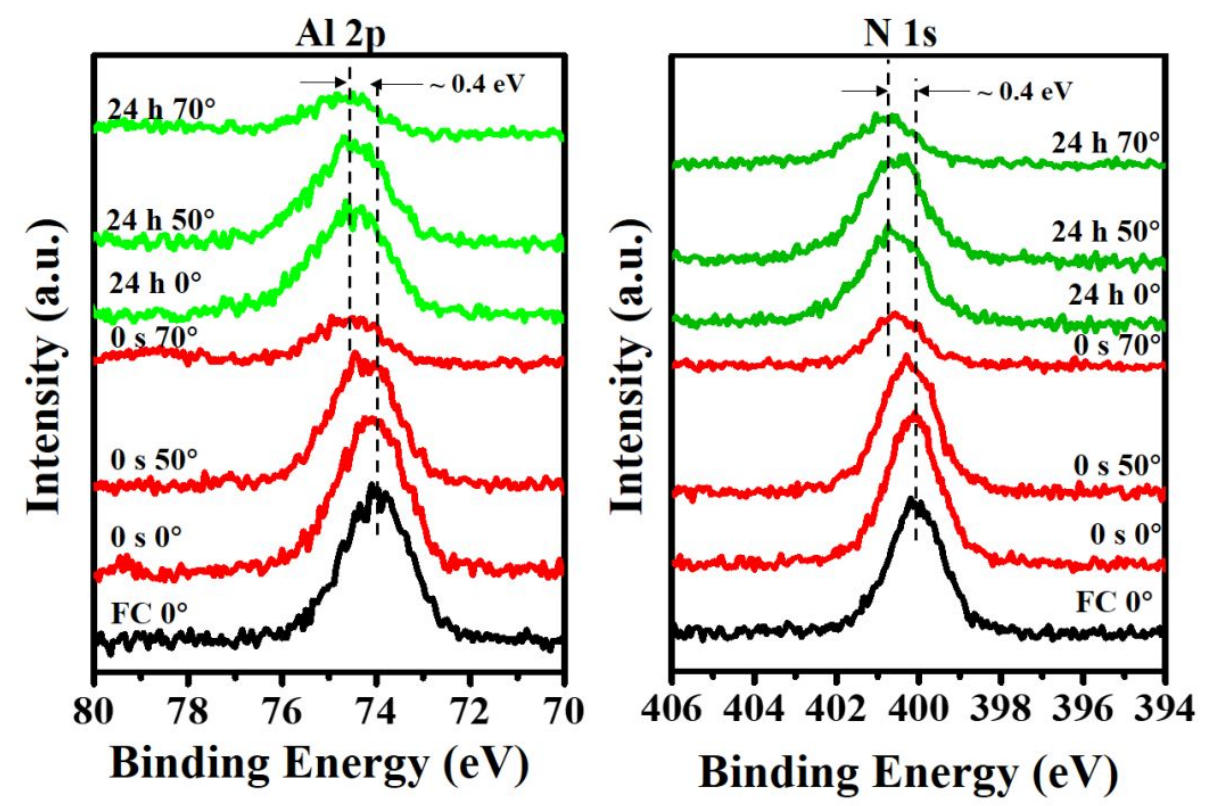

Figure S23. ARXPS Al 2p and N 1s signals of the fully charged (FC) electrode, OC in UHV after removing the charging bias ( $0 \mathrm{~s})$ and $\mathrm{OC}$ for $24 \mathrm{~h}$. As described in the article, the chemical state of the topmost surface region changes once the external electric field is removed (data of $0 \mathrm{~s} / 70^{\circ}$ ). After $24 \mathrm{~h}$, the electronic structure from the topmost surface region to near surface region becomes uniform and the BEs are $0.4 \mathrm{eV}$ lower than FC state. 

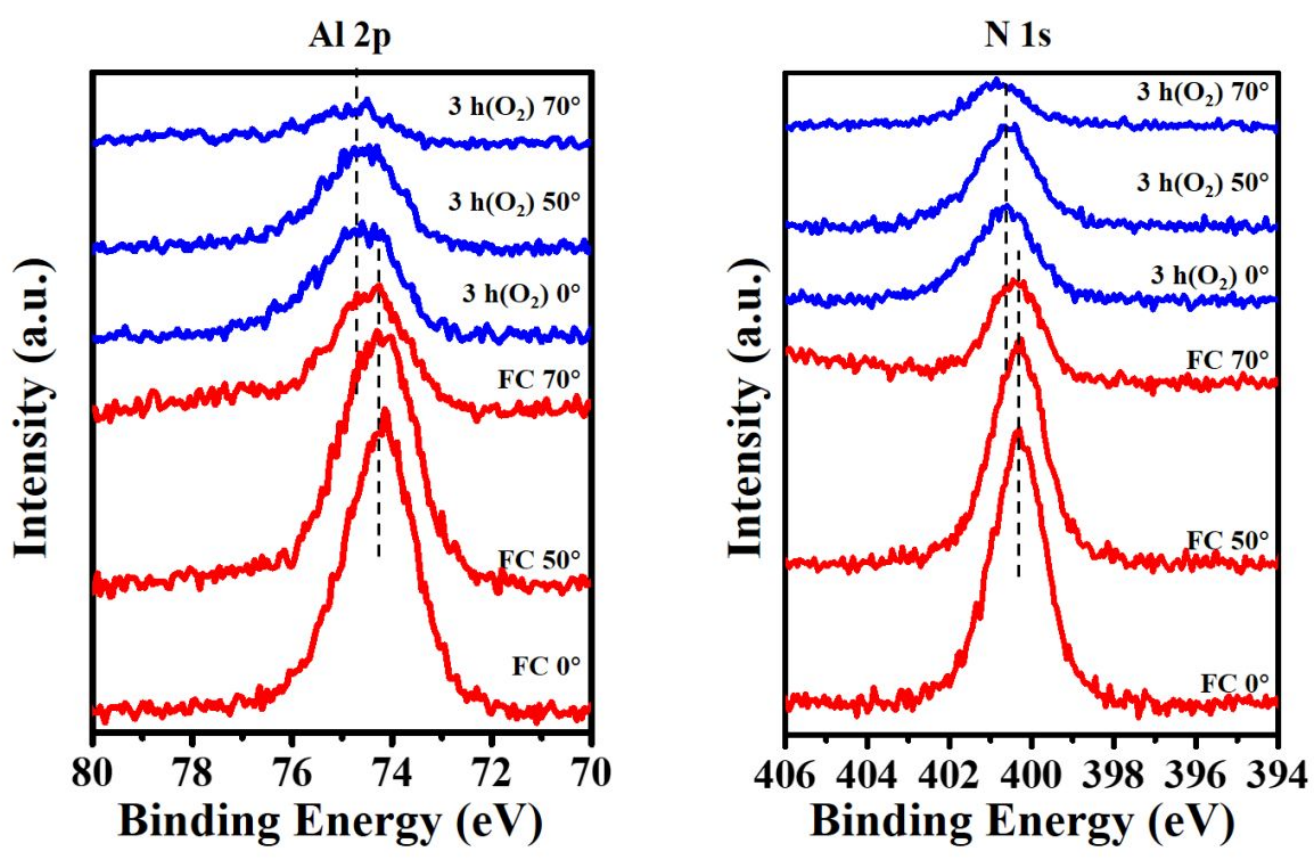

Figure S24. ARXPS Al $2 p$ and N 1s signals of the fully charged (FC) state and after being exposed to $1 \times 10^{-6} \mathrm{mbar}_{2}$ for $180 \mathrm{~min}$. 

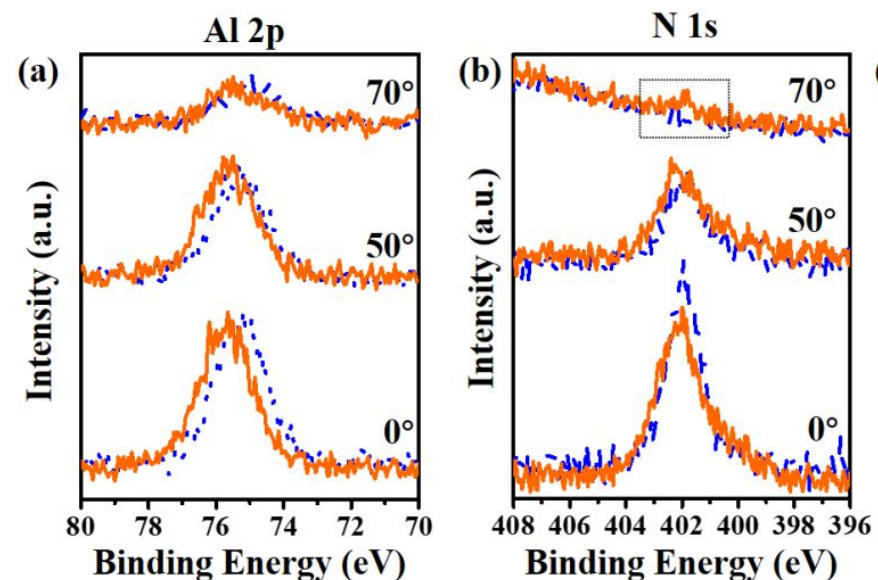

(e)

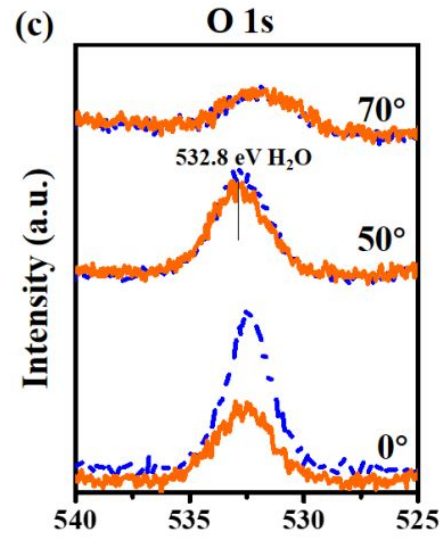

Binding Energy (eV)

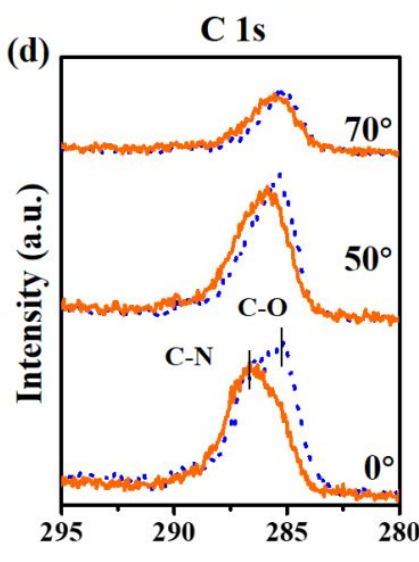

Binding Energy (eV)

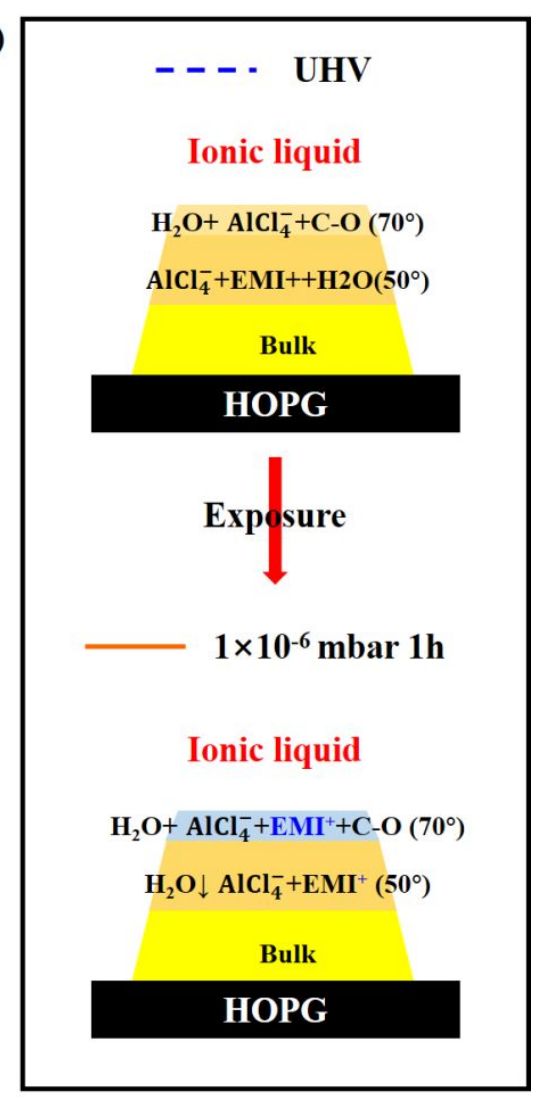

Charge redistribution

Figure S25. Depth-dependent chemical information of the ionic liquid (IL) droplet in $\mathrm{UHV}$ and after exposure to $1 \times 10^{-6} \mathrm{mbar}^{\mathrm{O}_{2}}$ for $1 \mathrm{~h}$ by ARXPS measurements.

ARXPS measurements have been carried out over a thin IL film which is dropped onto a HOPG crystal surface. For IL/UHV interface (blue dash line), the depthdependent distribution can be described as follows. ARXPS N 1s (b) spectra reveal that bare $\mathrm{EMI}^{+}$can be found in the topmost surface region considering the negligible $\mathrm{N} 1 \mathrm{~s}$ signal in ARXPS at $70^{\circ}$. So, the anion $\left(\mathrm{AlCl}_{4}^{-}\right)$is enriched in the topmost surface region for IL. In addition, at normal emission $\left(0^{\circ}\right)$ condition the asymmetric $\mathrm{C} 1 \mathrm{~s}(\mathrm{~d})$ is mainly composed of the $\mathrm{C}-\mathrm{N}$ in $\mathrm{EMI}^{+}$and some $\mathrm{C}-\mathrm{O}$ groups assigned to some organic impurity. Consistent with the ARXPS of N 1s, the C-O impurity is enriched in the topmost surface region while negligible $\mathrm{C}-\mathrm{N}$ signals can be found in the topmost surface region. The depth-dependent distribution of $\mathrm{O} 1 \mathrm{~s}$ is shown in (c). In normal emission $\left(0^{\circ}\right)$ condition, $\mathrm{O} 1 \mathrm{~s}$ is located at $\sim 532.5 \mathrm{eV}$. When the emission angle reaches $50^{\circ}$, a sharp $\mathrm{O} 1 \mathrm{~s}$ band of $\mathrm{H}_{2} \mathrm{O}$ can be found whose $\mathrm{BE}$ is the same as that of $\mathrm{H}_{2} \mathrm{O}$ at $\mathrm{OCV}$ state described in 
the article $(532.8 \mathrm{eV})$. In the topmost surface region, the broaden $\mathrm{O} 1 \mathrm{~s}$ should be composed of $\mathrm{H}_{2} \mathrm{O}$ and some C-O impurity whose BE is lower than $\mathrm{H}_{2} \mathrm{O}$. So, the depth distribution of the IL/UHV interface can be described by (e). In the topmost surface region $\left(70^{\circ}\right)$, the major component is $\mathrm{AlCl}_{4}^{-}, \mathrm{H}_{2} \mathrm{O}$ and some impurities. In the top surface region $\left(50^{\circ}\right)$, the major components are $\mathrm{AlCl}_{4}^{-}, \mathrm{EMI}^{+}$and $\mathrm{H}_{2} \mathrm{O}$. It should be mentioned that the anion is still excess in this case for the ratio $\mathrm{Al} / \mathrm{N}$ is 1.5 (theoretical value is 0.7$)$.

The $\mathrm{O}_{2}$-promoted charge redistribution process can be further clarified by the exposure of $\mathrm{O}_{2}$ to this thin IL film (orange solid line). Prominently, after exposure to 1 $\times 10^{-6}$ mbar $\mathrm{O}_{2}$ for $1 \mathrm{~h}$, the signal of $\mathrm{N} 1 \mathrm{~s}$ in the top most surface region (rectangular box in (b)) appears. Accordingly, the proportion of C-N in C 1s (d) increases after being exposed to $\mathrm{O}_{2}$. Consistent with the ARXPS measurements on the GIC electrode, the intensity of $\mathrm{O} 1 \mathrm{~s}$ decreases sharply (c) after exposure to $\mathrm{O}_{2}$. ARXPS measurements demonstrate that this is mainly caused by the reduction in $\mathrm{H}_{2} \mathrm{O}$ since $\mathrm{O}$ 1s in the topmost surface region (mainly assigned to impurity) has no obvious change. Therefore, after $\mathrm{O}_{2}$ treatment the redistribution of both anion/cation and $\mathrm{H}_{2} \mathrm{O}$ can be induced (e). The proportion of the cation $\left(\mathrm{EMI}^{+}\right)$in the topmost surface region increases while that of $\mathrm{H}_{2} \mathrm{O}$ in the surface region decreases. Such redistribution can also influence the chemical state of $\mathrm{AlCl}_{4}$ and lead to a positive BE shift of Al 2p (a). Overall, it can be concluded that the $\mathrm{O}_{2}$ can promote the redistribution of both anion/cation and $\mathrm{H}_{2} \mathrm{O}$, the underlying mechanisms may be attributed to the change of surface tension of the ion layers, which has been discussed in some previous works. ${ }^{17-18}$ 


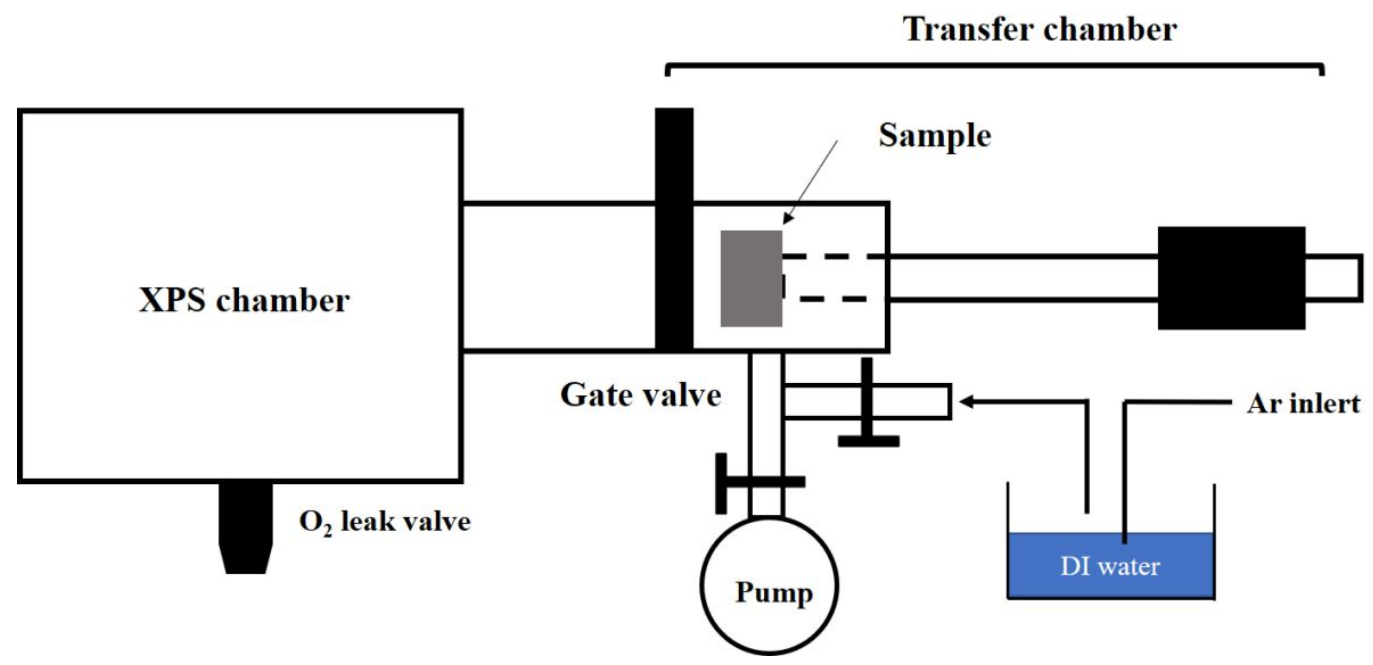

Figure S26. Diagram of the gas treatment systems and transfer chamber in XPS measurements. As described in the experimental section, the $\mathrm{H}_{2} \mathrm{O}$ treatment was carried out in the UHV transfer chamber (for transferring samples between the glove box and the XPS UHV chamber) by exposuing the sample to hydrous Ar (bubbling DI water). The low-pressure $\mathrm{O}_{2}$ treatment in UHV is performed by the $\mathrm{O}_{2}$ leak valve equipped on the XPS chamber. 
(a)

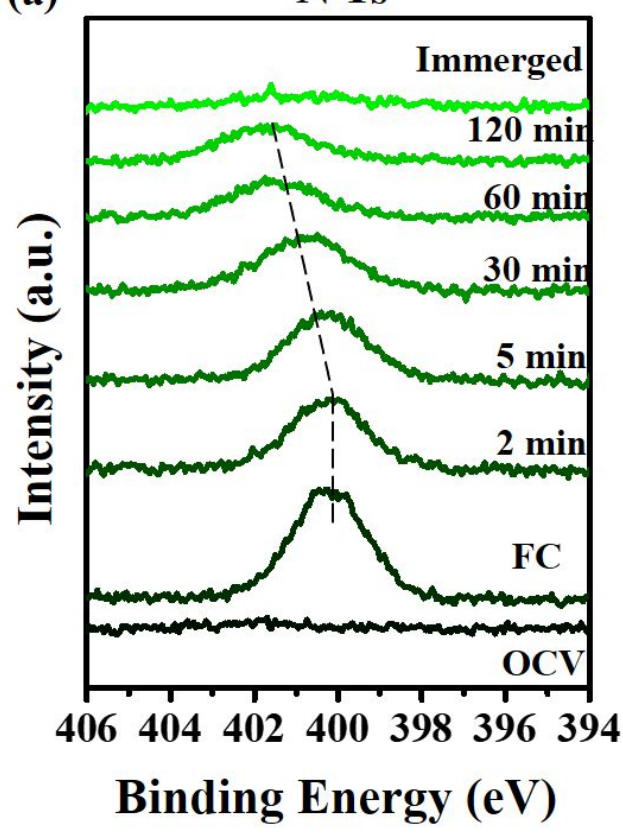

(b) Cl 2p

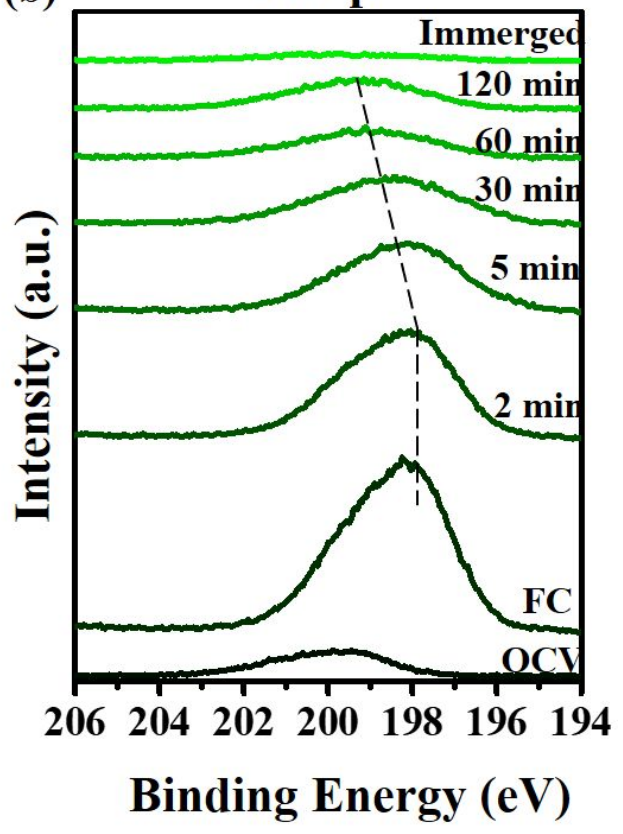

Figure S27. In situ XPS N 1s (a) and $\mathrm{Cl} 2 \mathrm{p}$ (b) signals in the $\mathrm{H}_{2} \mathrm{O}$-exposure experiments (Figure 3). Same as Al $2 p$ shown in Fig. $3 a$, the XPS Cl $2 p$ and N 1s signals undergo the intensity decrease and positive BEs shift. After exposure for $2 \mathrm{~h}$, the BEs of $\mathrm{N} 1 \mathrm{~s}$ and $\mathrm{Cl} 2 \mathrm{p}$ are close to the $\mathrm{OCV}$ state which are $\sim 1.5 \mathrm{eV}$ higher than the full charged (FC) state. 


\section{Supplementary electrochemical measurements results}

(a)

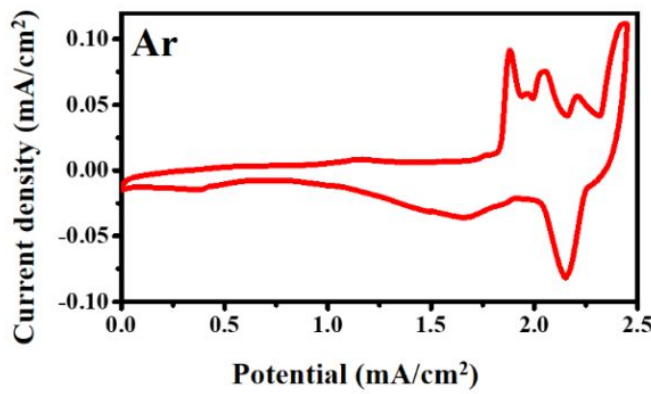

(b)

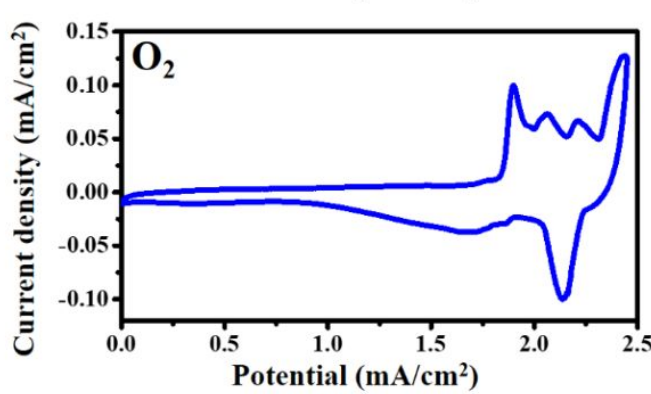

(c)

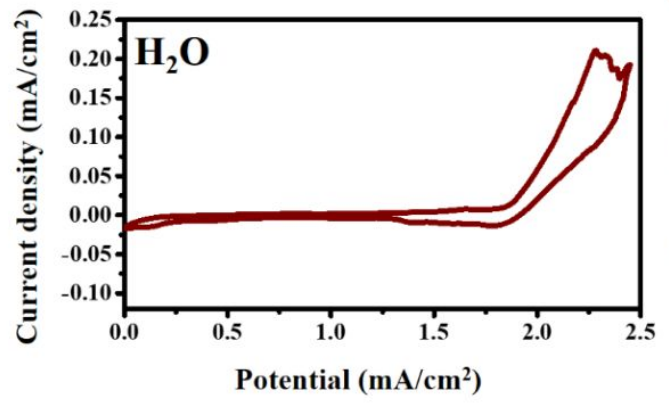

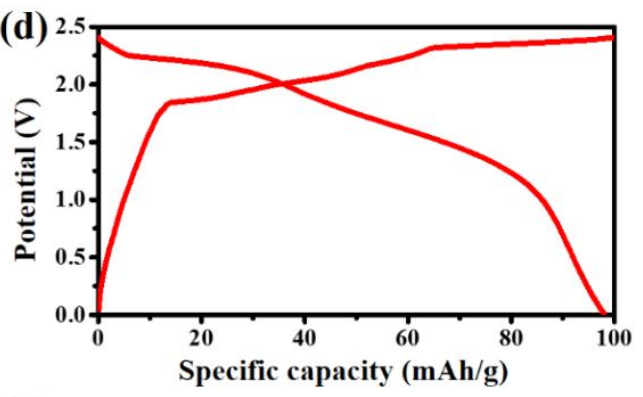

(e)

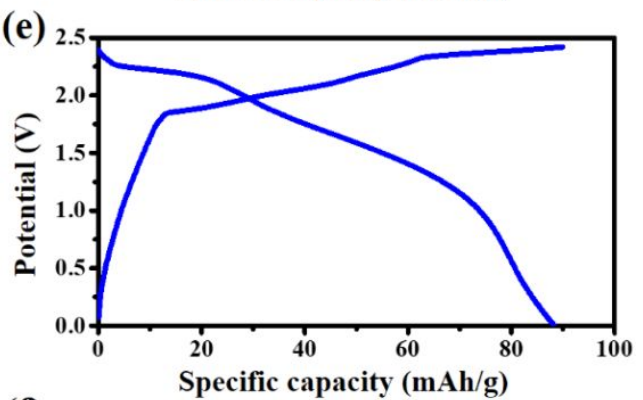

(f)

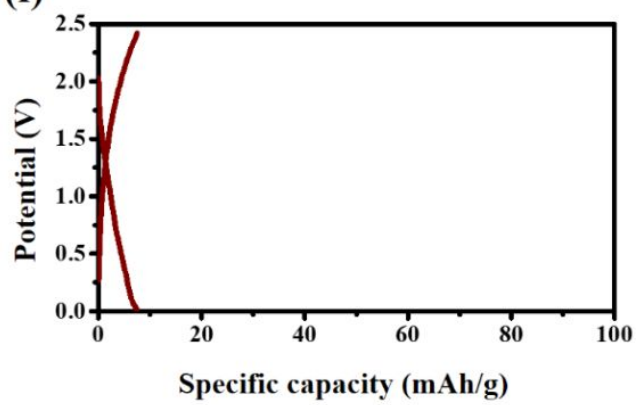

Figure S28. Cyclic voltammetry $(\mathrm{CV})$ curves $(0-2.45 \mathrm{~V}, 0.5 \mathrm{mV} / \mathrm{s})$ of the coin-type Al/graphite batteries after OC in $\mathrm{Ar}(\mathrm{a}), \mathrm{O}_{2}$ (b) and humidified $\mathrm{Ar}\left(\mathrm{H}_{2} \mathrm{O}\right.$, (c)) for 20000 $\mathrm{s}$ (Figure 4 (a) in the main text). Galvanostatic charge-discharge (GCD) curves (current density: $0.5 \mathrm{~A} / \mathrm{g}$, cutoff voltage: $2.42 \mathrm{~V}$ ) of the coin-type Al/graphite batteries after the $20^{\text {th }}$ cycle with different flowing gases (rate: $100 \mathrm{sccm}$ ): pure $\mathrm{Ar}(\mathrm{d}), \mathrm{O}_{2}$ (e) and $\mathrm{H}_{2} \mathrm{O}$ (f). As shown in (a), (b), (d) and (e) that $\mathrm{Ar}$ and $\mathrm{O}_{2}$ have negligible influence on the electrochemical behavior of the $\mathrm{Al} /$ graphite battery since the (de)intercalation peaks around 1.9, 2.1, 2.4 V (2.2 V, 1.5 V) and the (dis)charged plateaus in the range of 1.92.3 V, 2.3-2.4 V (2.2-2.0 V , 1.8-1.0 V) can be clearly seen. In addition, the discharging specific capacity in $\mathrm{O}_{2}(88 \mathrm{mAh} / \mathrm{g})$ is lower than in $\mathrm{Ar}(98 \mathrm{mAh} / \mathrm{g})$. Notably, after exposure to $\mathrm{H}_{2} \mathrm{O}$, the redox peaks in $\mathrm{CV}$ (c) become inconspicuous and irreversible. Meanwhile, the discharging specific capacity reduces to only $7 \mathrm{mAh} / \mathrm{g}(\mathrm{f})$. 


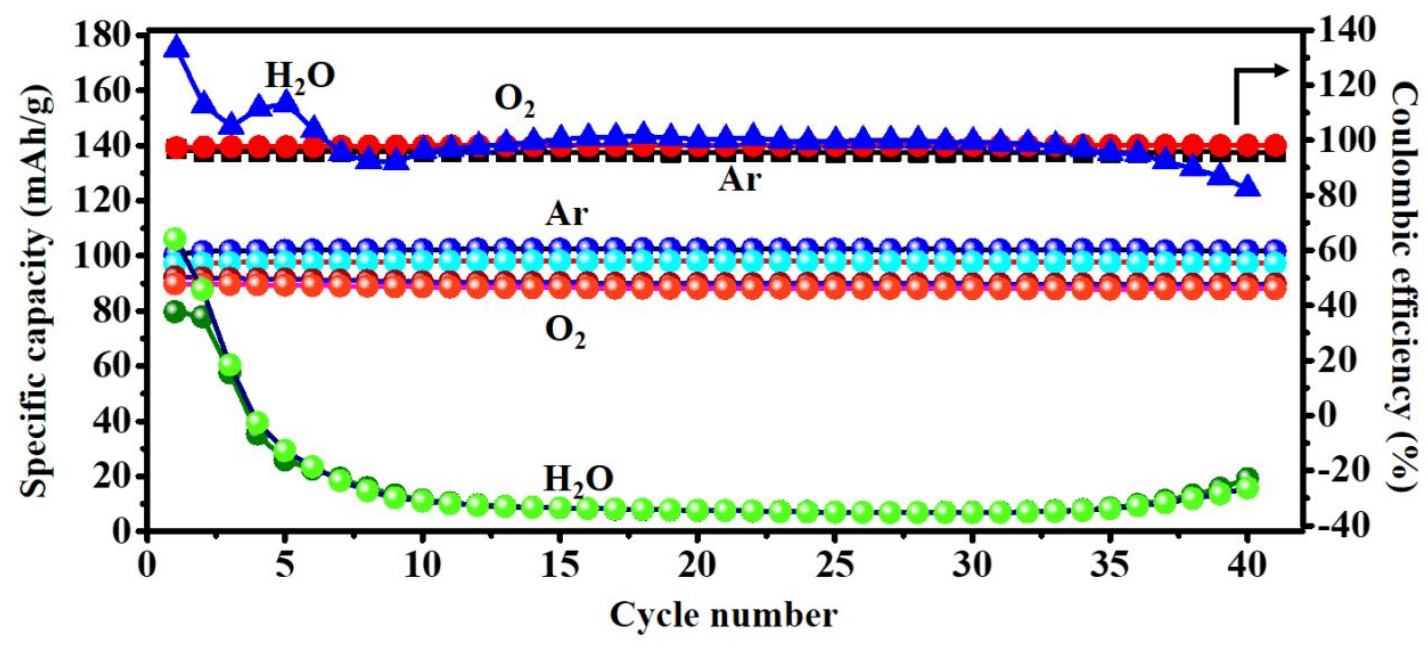

Figure S29. Cycling performance of the coin-type Al/graphite batteries at $0.5 \mathrm{~A} / \mathrm{g}$ with three different flowing gases of $\mathrm{Ar}, \mathrm{O}_{2}$ and $\mathrm{H}_{2} \mathrm{O}$. The detailed charging/discharging specific capacity and the coulombic efficiency are illustrated. As discussed in the main text, no capacity loss can be found in Ar during cycling and the capacity maintains at $\sim 100 \mathrm{mAh} / \mathrm{g}$ over 40 cycles with the coulombic efficiency of around $96 \%$. In $\mathrm{O}_{2}$, the capacity during cycling is lower than that in Ar. After 40 cycles, the discharge capacity is reduced to $88 \mathrm{mAh} / \mathrm{g}$ from $90 \mathrm{mAh} / \mathrm{g}(\sim 2 \%)$. Notably, after exposure to $\mathrm{H}_{2} \mathrm{O}$, the first 5 cycles perform abnormal high coulombic efficiency ( $>100 \%)$ which may be attributed to the side reactions. Afterward, the charging/discharging capacity is stabilized at $\sim 7$ $\mathrm{mAh} / \mathrm{g}$, i.e. close to $\sim 100 \%$ capacity loss. Overall, the electrochemical data are highly consistent with the characterization results that the $\mathrm{H}_{2} \mathrm{O}$ is the main factor of the performance failure. 


\section{In situ visualization of the failure behavior in LIB}
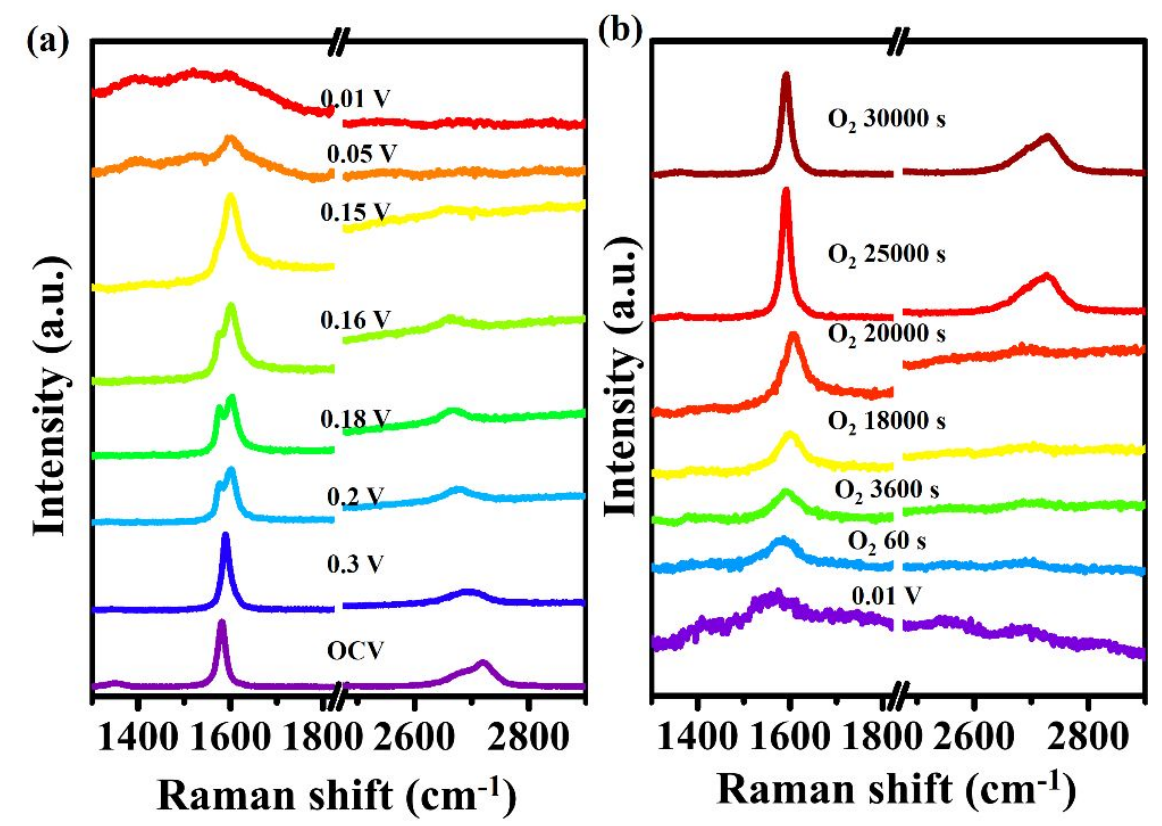

Figure S30. Operando and in situ Raman measurements over the Li/graphite model battery with the commercial electrolyte (LB092: $1 \mathrm{M} \mathrm{LiPF}_{6}$ in EC-DEC-DMC (1:1:1 by volume)-1\% VC) upon discharging and subsequent exposure to $\mathrm{O}_{2}$.

The operando Raman results upon discharging are similar to the previous work. ${ }^{19}$ Briefly, the $\mathrm{G}$ band first upshifts to $1589 \mathrm{~cm}^{-1}$ at $0.3 \mathrm{~V}$ from $1581 \mathrm{~cm}^{-1}$ at $\mathrm{OCV}(\sim 2.9$ V) and meanwhile the 2D band shifts from $2719 \mathrm{~cm}^{-1}$ to $2700 \mathrm{~cm}^{-1}$, revealing a dilute stage-1 phase has been formed. When the potential reaches $0.2 \mathrm{~V}$, two new bands at $1575 \mathrm{~cm}^{-1}$ and $1602 \mathrm{~cm}^{-1}$ can be observed which are assigned to the uncharged $\left(\mathrm{G}_{\mathrm{uc}}\right)$ and charged graphene layer $\left(\mathrm{G}_{\mathrm{c}}\right)$ in the stage-4 Li-GIC respectively. With the potential decreasing, the intensity of the $\mathrm{G}_{\mathrm{c}}$ band increases and becomes dominant at $0.15 \mathrm{~V}$ which indicates a stage-2 Li-GIC has formed. Afterward, the intensity of the $\mathrm{G}_{\mathrm{c}}$ band dramatically decreases and almost disappears at $0.01 \mathrm{~V}$, revealing the formation of $\mathrm{LiC}_{6}$ GIC. After exposure to $\mathrm{O}_{2}$, a small Raman peak at $1573 \mathrm{~cm}^{-1}$ can be observed for $60 \mathrm{~s}$. With prolonged $\mathrm{O}_{2}$ exposure, the intensity of this Raman wave increases along with the slight upshift. After $25000 \mathrm{~s}$, the sharp G band at $1581 \mathrm{~cm}^{-1}$ and the asymmetric 2D band at $2718 \mathrm{~cm}^{-1}$ are found which is almost the same with that seen for the graphite electrode at OCV state. Such results demonstrate that, after exposure to $\mathrm{O}_{2}$, the intercalated $\mathrm{Li}^{+}$is converted into lithium oxide and induce the decoupling with the graphite host, analogous to the failure behaviors of AIB in hydrous atmosphere. 


\section{Reference}

(1) Lin, M. C.; Gong, M.; Lu, B. G.; Wu, Y. P.; Wang, D. Y.; Guan, M. Y.; Angell, M.; Chen, C. X.; Yang, J.; Hwang, B. J.; Dai, H. J., An Ultrafast Rechargeable Aluminium-ion Battery. Nature 2015, 520 (7547), 325-328.

(2) Wang, C.; Ning, Y.; Huang, H.; Li, S.; Fu, Q., Operando Surface Science Methodology Reveals Surface Effect in Charge Storage Electrodes. Natl. Sci. Rev. 2021, 8 (3), nwaa289.

(3) Cao, J. Y.; He, P.; Mohammed, M. A.; Zhao, X.; Young, R. J.; Derby, B.; Kinloch, I. A.; Dryfe, R. A. W., Two-Step Electrochemical Intercalation and Oxidation of Graphite for the Mass Production of Graphene Oxide. J. Am. Chem. Soc. 2017, 139 (48), 17446-17456.

(4) Yang, C. Y.; Chen, J.; Ji, X.; Pollard, T. P.; Lu, X. J.; Sun, C. J.; Hou, S.; Liu, Q.; Liu, C. M.; Qing, T. T.; Wang, Y. Q.; Borodin, O.; Ren, Y.; Xu, K.; Wang, C. S., Aqueous Li-ion battery enabled by halogen conversion-intercalation chemistry in graphite. Nature 2019, 569 (7755), 245-250.

(5) Li, Y.; Lu, Y. X.; Adelhelm, P.; Titirici, M. M.; Hu, Y. S., Intercalation Chemistry of Graphite: Alkali Metal Ions and Beyond. Chem. Soc. Rev. 2019, 48 (17), 4655-4687.

(6) Zhao, W. J.; Tan, P. H.; Liu, J.; Ferrari, A. C., Intercalation of Few-Layer Graphite Flakes with $\mathrm{FeCl}_{3}$ : Raman Determination of Fermi Level, Layer by Layer Decoupling, and Stability. J. Am. Chem. Soc. 2011, 133 (15), 5941-5946.

(7) Zhan, D.; Sun, L.; Ni, Z. H.; Liu, L.; Fan, X. F.; Wang, Y.; Yu, T.; Lam, Y. M.; Huang, W.; Shen, Z. X., $\mathrm{FeCl}_{3}$-Based Few-Layer Graphene Intercalation Compounds: Single Linear Dispersion Electronic Band Structure and Strong Charge Transfer Doping. Adv. Funct. Mater. 2010, 20 (20), 3504-3509.

(8) Schmuelling, G.; Placke, T.; Kloepsch, R.; Fromm, O.; Meyer, H.-W.; Passerini, S.; Winter, M., Xray Diffraction Studies of the Electrochemical Intercalation of Bis(trifluoromethanesulfonyl)imide Anions into Graphite for Dual-ion Cells. J. Power Sources 2013, 239, 563-571.

(9) Pan, C. J.; Yuan, C. Z.; Zhu, G. Z.; Zhang, Q.; Huang, C. J.; Lin, M. C.; Angell, M.; Hwang, B. J.; Kaghazchi, P.; Dai, H. J., An Operando X-ray Diffraction Study of Chloroaluminate Anion-graphite Intercalation in Aluminum Batteries. Proc. Natl. Acad. Sci. U. S. A. 2018, 115 (22), 5670-5675.

(10) Wang, D.-Y.; Huang, S.-K.; Liao, H.-J.; Chen, Y.-M.; Wang, S.-W.; Kao, Y.-T.; An, J.-Y.; Lee, Y.C.; Chuang, C.-H.; Huang, Y.-C.; Lu, Y.-R.; Lin, H.-J.; Chou, H.-L.; Chen, C.-W.; Lai, Y.-H.; Dong, C.L., Insights into Dynamic Molecular Intercalation Mechanism for Al-C battery by Operando Synchrotron X-ray Techniques. Carbon 2019, 146, 528-534.

(11) Foelske-Schmitz, A.; Weingarth, D.; Kotz, R., XPS Analysis of Activated Carbon Supported Ionic Liquids: Enhanced purity and reduced charging. Surf. Sci. 2011, 605 (23-24), 1979-1985.

(12) Foelske-Schmitz, A.; Weingarth, D.; Wokaun, A.; Koetz, R., Core Level Data of Ionic Liquids: Monitoring Charging by In Situ Electrochemical X-ray Photoelectron Spectroscopy. ECS Electrochem. Lett. 2013, 2 (4), H13-H15.

(13) Choi, S.; Go, H.; Lee, G.; Tak, Y., Electrochemical Properties of an Aluminum Anode in an Ionic Liquid Electrolyte for Rechargeable Aluminum-ion Batteries. Phys. Chem. Chem. Phys. 2017, 19 (13), 8653-8656.

(14) Dilasari, B.; Jung, Y.; Sohn, J.; Kim, S.; Kwon, K., Review on Corrosion Behavior of Metallic Materials in Room Temperature Ionic Liquids. Int. J. Electrochem. Sci. 2016, 11 (2), 1482-1495.

(15) Lovelock, K. R. J.; Smith, E. F.; Deyko, A.; Villar-Garcia, I. J.; Licence, P.; Jones, R. G., Water Adsorption on a Liquid Surface. ChemComm 2007, (46), 4866-4868. 
(16) Lexow, M.; Maier, F.; Steinrueck, H.-P., Ultrathin Ionic Liquid Films on Metal Surfaces: Adsorption, Growth, Stability and Exchange Phenomena. ADV PHYS-X 2020, 5 (1), 1761266.

(17) Kolbeck, C.; Lehmann, J.; Lovelock, K. R. J.; Cremer, T.; Paape, N.; Wasserscheid, P.; Froeba, A. P.; Maier, F.; Steinrueck, H. P., Density and Surface Tension of Ionic Liquids. J. Phys. Chem. B 2010, 114 (51), 17025-17036.

(18) Rietzler, F.; Nagengast, J.; Steinrueck, H. P.; Maier, F., Interface of Ionic Liquids and Carbon: Ultrathin $\mathrm{C}_{1} \mathrm{C}_{1} \mathrm{Im} \mathrm{Tf}_{2} \mathrm{~N}$ Films on Graphite and Graphene. J. Phys. Chem. C 2015, 119 (50), 28068-28076. (19) Inaba, M.; Yoshida, H.; Ogumi, Z.; Abe, T.; Mizutani, Y.; Asano, M., In Situ Raman Study on Electrochemical Li--intercalation into Graphite. J. Electrochem. Soc. 1995, 142 (1), 20-26. 